\title{
Low nitrogen availability inhibits the phosphorus starvation response in maize (Zea mays ssp. mays L.)
}

J. Vladimir Torres-Rodríguez ${ }^{1}$, M. Nancy Salazar-Vidal1,2,3, Ricardo A. Chávez Montes ${ }^{1,4}$, Julio A. Massange-Sánchez, C. Stewart Gillmor ${ }^{1}$ and Ruairidh J. H. Sawers ${ }^{1,6^{*}}$ (i)

\begin{abstract}
Background: Nitrogen $(N)$ and phosphorus $(P)$ are macronutrients essential for crop growth and productivity. In cultivated fields, $\mathrm{N}$ and $\mathrm{P}$ levels are rarely sufficient, contributing to the gap between realized and potential production. Fertilizer application increases nutrient availability, but is not available to all farmers, nor are current rates of application sustainable or environmentally desirable. Transcriptomic studies of cereal crops have revealed dramatic responses to either low $\mathrm{N}$ or low $\mathrm{P}$ single stress treatments. In the field, however, levels of both $\mathrm{N}$ and $\mathrm{P}$ may be suboptimal. The interaction between $\mathrm{N}$ and $\mathrm{P}$ starvation responses remains to be fully characterized.

Results: We characterized growth and root and leaf transcriptomes of young maize plants under nutrient replete, low N, low P or combined low NP conditions. We identified 1555 genes to respond to our nutrient treatments, in one or both tissues. A large group of genes, including many classical P starvation response genes, were regulated antagonistically between low $\mathrm{N}$ and $\mathrm{P}$ conditions. An additional experiment over a range of $\mathrm{N}$ availability indicated that a mild reduction in $\mathrm{N}$ levels was sufficient to repress the low $\mathrm{P}$ induction of $\mathrm{P}$ starvation genes. Although expression of $\mathrm{P}$ transporter genes was repressed under low $\mathrm{N}$ or low NP, we confirmed earlier reports of $\mathrm{P}$ hyper accumulation under $\mathrm{N}$ limitation.

Conclusions: Transcriptional responses to low $\mathrm{N}$ or $\mathrm{P}$ were distinct, with few genes responding in a similar way to the two single stress treatments. In combined NP stress, the low $N$ response dominated, and the $\mathrm{P}$ starvation response was largely suppressed. A mild reduction in $\mathrm{N}$ availability was sufficient to repress the induction of $\mathrm{P}$ starvation associated genes. We conclude that activation of the transcriptional response to $P$ starvation in maize is contingent on $\mathrm{N}$ availability.
\end{abstract}

Keywords: Maize, Phosphate, Nitrogen, Transcriptional regulation, SPX protein family

\footnotetext{
* Correspondence: ruairidh.sawers@gmail.com

${ }^{1}$ Laboratorio Nacional de Genómica para la Biodiversidad (Langebio), Unidad

de Genómica Avanzada, Centro de Investigación y de Estudios Avanzados

del Instituto Politécnico Nacional (CINVESTAV-IPN), Irapuato, C.P, 36824

Guanajuato, Mexico

${ }^{6}$ Department of Plant Science, The Pennsylvania State University, State

College, PA, USA

Full list of author information is available at the end of the article
}

(c) The Author(s). 2021 Open Access This article is licensed under a Creative Commons Attribution 4.0 International License, which permits use, sharing, adaptation, distribution and reproduction in any medium or format, as long as you give appropriate credit to the original author(s) and the source, provide a link to the Creative Commons licence, and indicate if changes were made. The images or other third party material in this article are included in the article's Creative Commons licence, unless indicated otherwise in a credit line to the material. If material is not included in the article's Creative Commons licence and your intended use is not permitted by statutory regulation or exceeds the permitted use, you will need to obtain permission directly from the copyright holder. To view a copy of this licence, visit http://creativecommons.org/licenses/by/4.0/ The Creative Commons Public Domain Dedication waiver (http://creativecommons.org/publicdomain/zero/1.0/) applies to the data made available in this article, unless otherwise stated in a credit line to the data. 


\section{Background}

Nitrogen $(\mathrm{N})$ and Phosphorus $(\mathrm{P})$ are essential macronutrients required for multiple biological processes [1-5]. $\mathrm{N}$ is a component of all proteins and the chlorophyll required for photosynthetic carbon fixation. $\mathrm{P}$ is required to produce the phospholipids forming the membranes that surround cells and intracellular organelles. Furthermore, $\mathrm{N}$ and $\mathrm{P}$ are structural components of nucleic acids, including the abundant RNA molecules that play a key role in protein synthesis. The demand for these macronutrients is such that $\mathrm{N}$ and $\mathrm{P}$ availability in agricultural soils is rarely sufficient to realize the full yield potential of crops $[6,7]$. $P$ reacts readily with other elements, such as aluminum in acid soils or calcium in alkaline soils, holding it in the upper layers of the soil and reducing its availability to plants $[8,9]$. By contrast, $N$, largely present in the form of nitrate, is mobile and tends to move to deeper soil layers where it may be beyond the reach of plant root systems [10]. In high-input systems, the problem of $\mathrm{N}$ and $\mathrm{P}$ limitation is mitigated by chemical fertilizer addition, although current levels of application are neither sustainable nor desirable given negative environmental impacts [11]. Industrial $\mathrm{N}$ fixation is energetically costly and contributes to greenhouse gas production [12]. High grade phosphate rock is a non-renewable resource, predicted to pass peak production before the end of this century [13]. For these reasons, increasing $\mathrm{N}$ and $\mathrm{P}$ efficiency has been identified as a key goal in plant breeding and agricultural management $[11,14]$.

Studies in Arabidopsis thaliana and rice (Oryza sativa) have identified physiological and developmental responses to low $\mathrm{N}$ or $\mathrm{P}$ stress, coupled with underlying large-scale changes in gene expression (the $\mathrm{N}$ starvation response - NSR, and P starvation response - PSR, respectively [15-20]). A common strategy under nutrient deficiency is to promote uptake by increasing the abundance of high-affinity transporter proteins in the roots. Under $\mathrm{N}$ or $\mathrm{P}$ limitation, there is an induction of genes encoding nitrate [21-23] or phosphate transporters [2427]), respectively. Further aspects of the NSR include the downregulation of genes associated with nitrate assimilation and amino acid, oligosaccharide and nucleic acid biosynthesis $[15,28]$. The PSR includes the induction of purple acid phosphatases (PAPs) involved in recycling internal and external $\mathrm{P}$ from organic pools, altered polysaccharide metabolism, and remodeling of lipid membranes to reduce the requirement for phospholipids [29-31]. Interestingly, aspects of the NSR and PSR are antagonistic and under $\mathrm{N}$ limitation many genes induced in the PSR are repressed $[15,30,32,33]$. It has long been appreciated that a deficiency in one element can impact the response to a second element, and that the effects of different nutrient deficiencies are not necessarily additive [34-40]. Thus, it is difficult to predict the transcriptomic response to a combination of $\mathrm{N}$ and $\mathrm{P}$ deficiency from the single stress data, especially in the context of antagonistically regulated genes. Several studies, however, have now demonstrated clear points of molecular interaction between $\mathrm{N}$ and $\mathrm{P}$ signaling pathways.

One of the first molecular links between N and P signaling was the identification of the SPX-RING (SPX domain: named after the Suppressor of Yeast gpa1, the yeast Phosphatase 81 and the human Xenotropic and Polytropic Retrovirus receptor 1; RING domain: Really Interesting New Gene) protein NITROGEN LIMITATI ON ADAPTATION (NLA1) in Arabidopsis. Atnla1 mutants fail to adapt to low $\mathrm{N}$ conditions and exhibit early senescence [41] associated with $\mathrm{P}$ toxicity [42]. Further studies have shown that AtNLA directly targets PHT1 phosphate transporters for degradation in a $\mathrm{N}$ dependent manner [43] as well as targeting the nitrate transporter NRT1.7 [44]. Under P starvation, downregulation of $A t N L A$ by the $\mathrm{P}$ starvation inducible microRNA miR827 promotes accumulation of PHT1 [42]. Rice OsNLA also regulates PHT1 abundance and modulates P accumulation in an $\mathrm{N}$-dependent manner $[45,46]$. However, in rice, miR827 does not target OsNLA, nor do $\mathrm{N}$ and $\mathrm{P}$ levels regulate $O s N L A$ transcript accumulation, indicating regulatory differences with Arabidopsis [45, 47].

The MYB-CC transcription factor AtPHR1 plays a central role in activating the PSR [48]. Under high P, OsPHR2, the rice ortholog of AtPHR1, is sequestered by the SPX protein OsSPX4 preventing its translocation into the nucleus and activation of PSR genes [49]. Under $\mathrm{P}$ starvation, the $26 \mathrm{~S}$ proteasome degrades OsSPX4, allowing OsPHR2 to activate its targets. Recently, the Nregulated OsNRT1.1b nitrate transporter has been shown to be required for OsSPX4 degradation. Under $\mathrm{N}$ starvation, levels of OsNRT1.1b are reduced, freeing OsSPX4 from turnover and leading to inhibition of the PSR [50]. Interestingly, OsSPX4 not only sequesters OsPHR2, but also the NIN-like protein OsNLP3, a central regulator of nitrogen response in rice [50]. These studies, and others, have demonstrated the interaction of $\mathrm{N}$ and $\mathrm{P}$ responses, and identified the SPX domain containing proteins as playing an important role in their coordination.

Maize is one of the world's most economically important crops. Limitation of $\mathrm{N}$ or $\mathrm{P}$ represents a significant constraint on maize productivity worldwide [51-54]. Work in Arabidopsis and rice has begun to define the interactions between $\mathrm{N}$ and $\mathrm{P}$ signaling networks. Nevertheless, much remains to be discovered before we can apply this knowledge to the design of more efficient management practices or the development of more nutrient efficient crop varieties. Here, we report whole transcriptome data for the leaves and roots of maize seedlings grown in nutrient replete, low $\mathrm{N}$, low $\mathrm{P}$ and a 
combined low NP stress. We observed antagonism between responses to single low $\mathrm{N}$ and low $\mathrm{P}$ treatments, with the low $\mathrm{N}$ response dominating in the combined low NP treatment. We further show that even a mild reduction in $\mathrm{N}$ availability is sufficient to suppress components of the maize PSR.

\section{Results}

\section{Growth of maize seedlings was reduced under low $\mathrm{N}$ and} $P$ treatments

To select material in which to characterize transcriptional responses to combined $\mathrm{N}$ and $\mathrm{P}$ limitation, we first characterized the growth of maize plants grown for 40 days after emergence under complete nutrient conditions (Full; see Methods), reduced N (LowN: 9\% of complete concentration), reduced P (LowP: 3\% of complete concentration), and under combined reduced $\mathrm{N}$ and $\mathrm{P}$ (LowNP). Plants were grown in $1 \mathrm{~m}$ tall, $15 \mathrm{~cm}$ diameter ( $\sim 17 \mathrm{~L}$ volume) PVC tubes, providing sufficient depth for root development (Fig. 1a). We followed plant growth by manual measurement of green leaf area (LA) every 5 days, starting at 10 days after emergence (DAE). Plants in Full conditions showed an increase in the rate of leaf initiation compared with reduced nutrient treatments (Fig. 1b; S1; MZ66_Growth_Analysis in Additional file 7: Supplemental File 1). At 25 DAE, Full and LowP plants had initiated $\sim 1$ more leaf than LowN and LowNP plants (KW adj. $p=0.003$. Dunn test at $\alpha=$ 0.05. Leaf number - Full: $5.6 \pm 0.2 \mathrm{a}$; LowP: $5.0 \pm 0.22 \mathrm{a}$; LowN: $4.0 \pm 0.22 \mathrm{~b}$; LowP: $4.1 \pm 0.2 \mathrm{~b}$. Here and below, we give model coefficients, standard errors and means groups assigned by Dunn test or Tukey as indicated). By harvest, plants in Full had $\sim 1.5$ more leaves on than those in the stress treatments, with the stress treatments indistinguishable among themselves (KW adj. $p=0.09$. Dunn test at $\alpha=0.05$. Leaf number 40 DAE - Full: $8.6 \pm$ $0.28 \mathrm{a}$; LowP: $7.3 \pm 0.32 \mathrm{~b} ;$ LowN: $7.0 \pm 0.33 \mathrm{~b} ;$ LowNP: $7.0 \pm 0.29 \mathrm{~b})$. The first two leaves were fully expanded in all treatments when we started to collect measurements at $10 \mathrm{DAE}$, and they began to senesce early in the course of the experiment, reflected by a loss of LA (Fig. 1c,d). Second leaves showed equivalent LA in all treatments (Leaf 2 LA - KW adj. $p>0.05$ for treatment at all time points) and began to senesce at the same time $(\sim 30$ DAE; Fig. 1d). Senescence began earlier in first leaves than second leaves $(\sim 20 \mathrm{DAE})$, and was more rapid under LowN and LowNP than in the other conditions (Fig. 1c. Leaf 1 - LA KW adj. $p<0.001$ at 25 and 30 DAE. Dunn test at $\alpha=0.05$. First leaves senesced completely by day 25 under LowN and LowNP, but not until 40 DAE under Full and LowP). Third leaves were present at the first time point, continuing to grow until $\sim 20$ DAE, with no difference in LA between treatments (Fig. 1e. Leaf 3 LA - KW adj. $p>0.05$ for treatment at all time points). Later leaves were initiated during the experiment, showing growth differences between treatments (Fig. 1f-j; S1; MZ66_Growth_Analysis in Supplemental File 1). Treatment differences became more dramatic with each leaf to be initiated. In fourth leaves, we observed a mild treatment effect from $\sim 10$ days after leaf expansion (Leaf 4 LA 20 DAE - KW adj. $p=0.044$ ), leaves of the LowNP plants having a lower surface area than those of the other treatments (Fig. 1g; Dunn test at $\alpha=0.05$ ). Differences in the later leaves were evident within 5 days after initiation, the timing of initiation also becoming delayed in the low nutrient treatments. By the sixth and seventh leaves, we observed a difference between Full, LowP and LowN/LowNP treatments (Fig. 1h,i; S1; MZ66_Growth_Analysis in Supplemental File 1; leaf 6 LA, 30 DAE - KW adj. $p<$ 0.001; leaf 7 LA, 35 DAE - KW adj. $p<0.001$; Dunn test at $\alpha=0.05$; differences maintained until $40 \mathrm{DAE})$. Plants in the Full treatment also produced eighth (Fig. 1j) and some ninth (not shown) leaves before the end of the experiment. In addition to photosynthetic surface area, plant stature clearly differed among treatments, as captured by measurement of stem height (Fig. 1j; S1; MZ66_Growth_Analysis in Supplemental File 1). By 20 DAE, Full and LowP plants were taller than LowN and LowNP plants (Fig. 1k. Stem height $-\mathrm{KW}$ adj. $p=0.011$; Dunn test at $\alpha=0.05$. Stem height 20 DAE - Full: 5.76 $\mathrm{cm} \pm 0.48 \mathrm{a}$; LowP: $5.59 \mathrm{~cm} \pm 0.53 \mathrm{a}$; LowN: $4.09 \mathrm{~cm} \pm$ 0.54b; LowNP: $3.83 \mathrm{~cm} \pm 0.48 \mathrm{~b}$ ), a pattern maintained until harvest. Treatment had a significant effect on total leaf area by $20 \mathrm{DAE}$ (Fig. 11; Square root transformed total LA 20 DAE - KW adj. $p<0.05$; Dunn test at $\alpha=$ 0.05 . Full: $7.16 \mathrm{~cm} \pm 0.46 \mathrm{a}$; LowP: $6.72 \mathrm{~cm} \pm 0.52 \mathrm{a}$; LowN: $5.82 \mathrm{~cm} \pm 0.53 \mathrm{ab} ;$ LowNP: $4.72 \mathrm{~cm} \pm 0.47 \mathrm{~b})$. By harvest, the four treatments could be distinguished by total leaf area (Fig. 1l; Square root transformed total LA 40 DAE KW adj. $p<0.001$; Dunn test at $\alpha=0.05$. Full: $19.90 \mathrm{~cm}$ $\pm 1.02 \mathrm{a}$; LowP: $13.55 \mathrm{~cm} \pm 1.14 \mathrm{ab} ;$ LowN: $9.15 \mathrm{~cm} \pm$ $1.17 \mathrm{bc}$; LowNP: $8.35 \mathrm{~cm} \pm 1.04 \mathrm{c}$ ). We used the slope of a linear fit through the plot of square root transformed total LA on time as an estimate of growth in each treatment and observed differences between all four treatments, with a ranking of Full, LowP, LowN, LowNP (Fig. S2; MZ66_Endpoint_Analysis in Supplemental File 1. Growth - KW adj. $p<0.001$; Dunn test at $\alpha=0.05$. Full: $0.45 \mathrm{~cm} /$ day $\pm 0.02 \mathrm{a}$; LowP: $0.34 \mathrm{~cm} /$ day $\pm 0.02 \mathrm{ab}$; LowN: $0.25 \mathrm{~cm} /$ day $\pm 0.02 \mathrm{bc}$; LowNP: $0.22 \mathrm{~cm} /$ day $\pm 0.02 \mathrm{c}$ ).

At $40 \mathrm{DAE}$, plants were harvested by careful removal from the PVC tubes and endpoint measurements taken for roots and the aerial portions of the plant. Plants under Full treatment were clearly larger than those under the stress treatments, while the three stress treatments were partially separated (Fig. 2a, b. MZ66_Endpoint_Analysis in Supplemental File 1. Root fresh weight - KW adj. $p<$ 


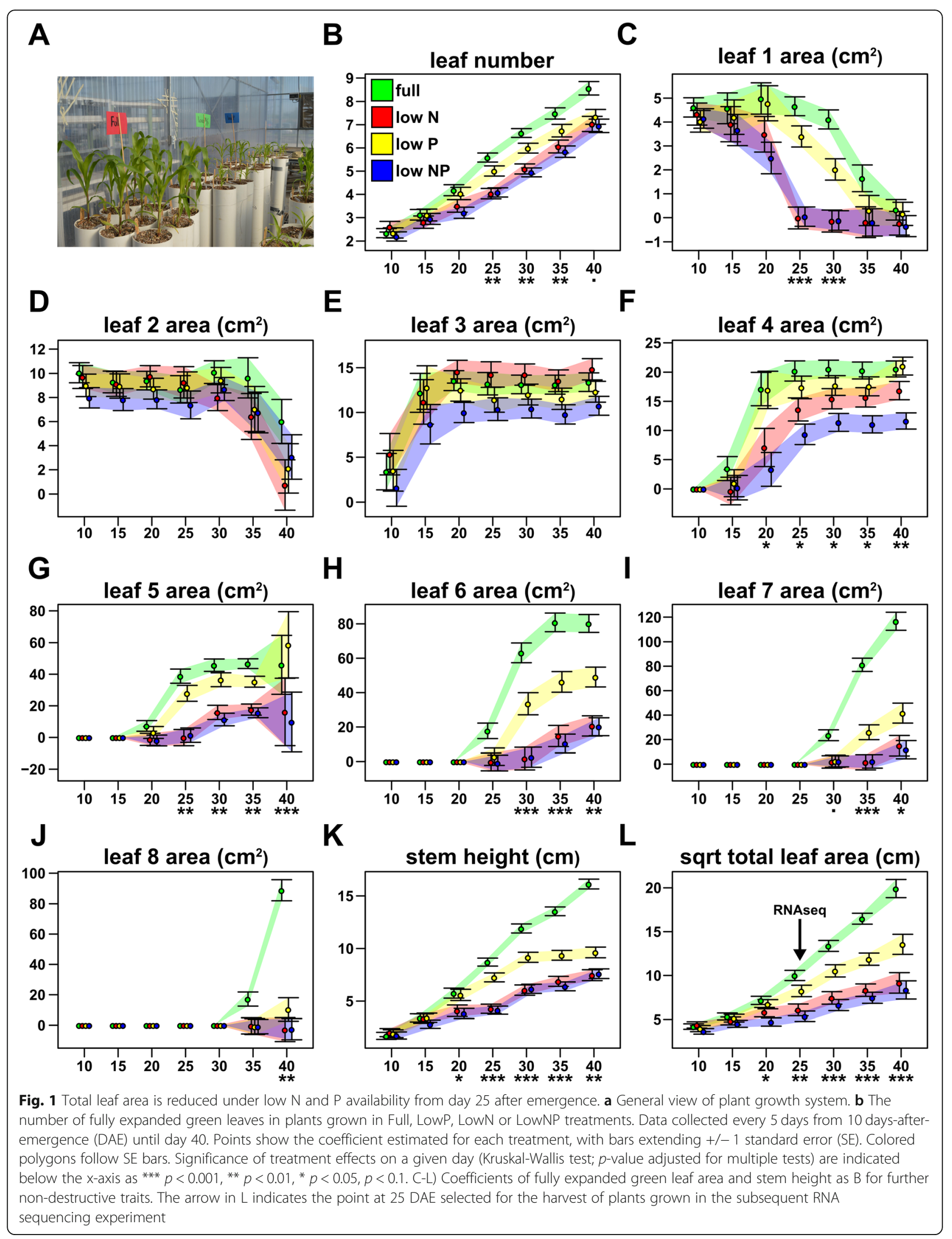




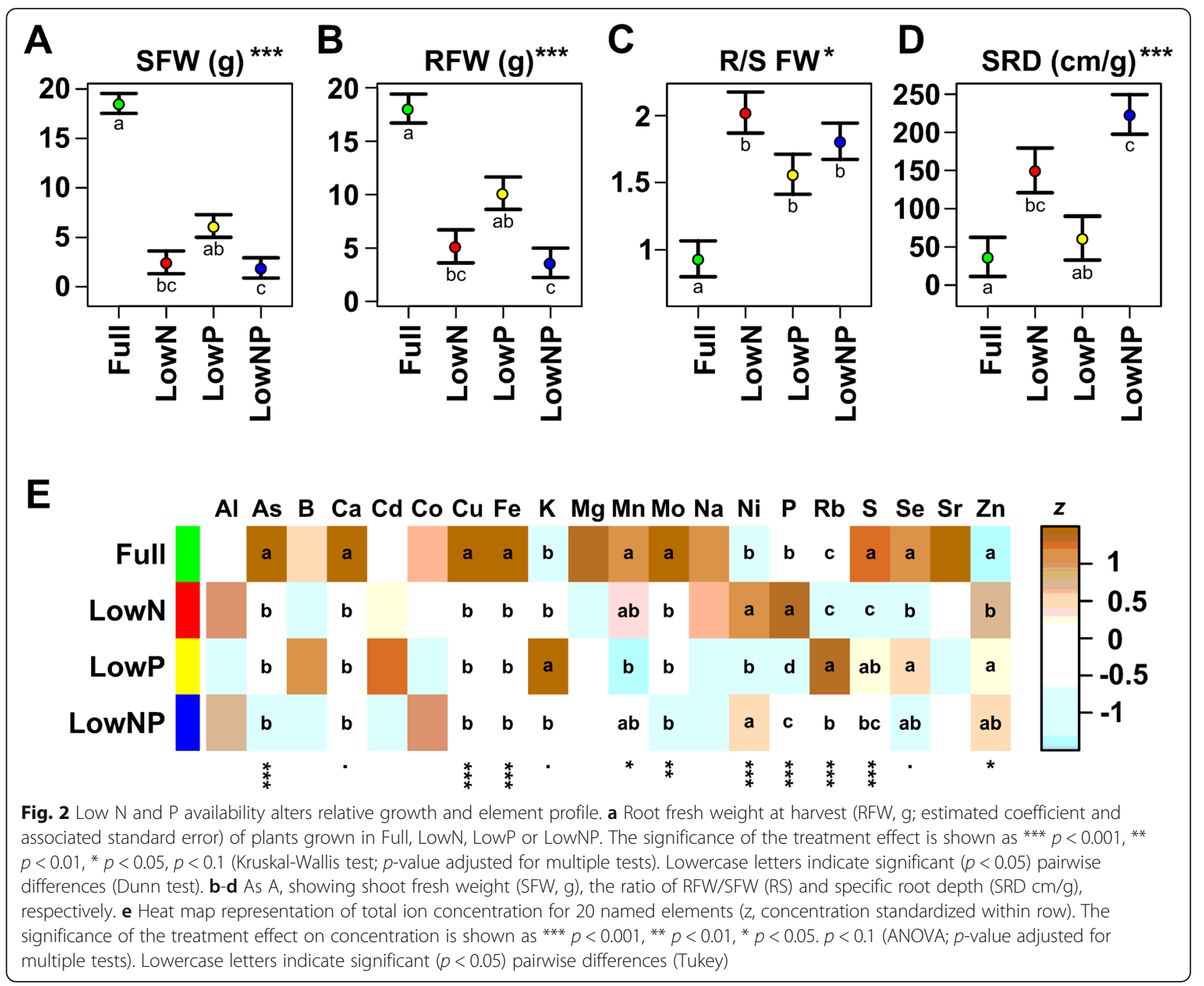

0.001; Dunn test at $\alpha=0.05$. Full: $18.07 \mathrm{~g} \pm 1.36 \mathrm{a}$; LowP: $10.13 \mathrm{~g} \pm 1.52 \mathrm{ab} ;$ LowN: $5.17 \mathrm{~g} \pm 1.55 \mathrm{bc}$; LowNP: $3.62 \mathrm{~g} \pm$ 1.37c. Shoot fresh weight $-\mathrm{KW}$ adj. $p<0.001$; Dunn test at $\alpha=0.05$. Full: $18.55 \mathrm{~g} \pm 1.00 \mathrm{a}$; LowP: $6.14 \mathrm{~g} \pm 1.13 \mathrm{ab}$; LowN: $2.48 \mathrm{~g} \pm 1.15 \mathrm{bc}$; LowNP: $1.91 \mathrm{~g} \pm 1.02 \mathrm{c}$ ). The root: shoot ratio (fresh weight) was greater under stress treatments, with an increase of 2.2-, 1.7- and 1.9- fold with respect to Full under LowN, LowP and LowNP, respectively (Fig. 2c). Plants under LowP and LowNP showed greater root system depth (RSD) than those under Full or LowN conditions, although the treatment effect was not significant (RSD KW adj. $p=1$ ). Specific root depth (SRD), calculated as RSD over total root fresh weight, did vary significantly among treatments, with LowN and LowNP showing higher values than LowP and Full treatments (Fig. 2d. MZ66_Endpoint_Analysis in Supplemental File 1. SRD - KW adj. $p<0.001$; Dunn test at $\alpha=0.05$. LowNP: $19.12 \mathrm{~cm} / \mathrm{g} \pm 1.46 \mathrm{c} ; \quad$ LowN: $13.37 \mathrm{~cm} / \mathrm{g} \pm 1.65 \mathrm{bc} ; \quad$ LowP: $9.49 \mathrm{~cm} / \mathrm{g} \pm 1.62 \mathrm{ab} ;$ Full: $5.02 \mathrm{~cm} / \mathrm{g} \pm 1.44 \mathrm{a})$.
To further characterize differences in root system architecture (RSA) among nutrient treatments, we photographed the roots of each plant and processed the images using GiaRoots analysis software [55] to extract a series of root features. Nutrient treatment had a significant effect on several features related to root system size (Fig. S3; MZ66_Giaroots_Analysis in Supplemental File 1) including network area, perimeter and volume and the maximum and median number of roots crossing a horizontal line in a vertical scan (see [55] for a complete description of root features). The Full treatment was associated with the largest, most solid root systems, followed by LowP, LowN and LowNP. We also saw a significant effect on the ratio of the minor/major axes (EAR) of an ellipse fitted around the root system (EAR - KW adj. $p=0.016$; Dunn test at $\alpha=0.05$. Full: $0.46 \pm 0.03 \mathrm{a} ; \quad$ LowP: $0.40 \pm 0.04 \mathrm{a} ; \quad$ LowN: $0.36 \pm 0.04 \mathrm{a}$; LowNP: $0.29 \pm 0.03 \mathrm{~b})$. EAR reflects the tendency to relatively narrower but deeper root systems in the low 
nutrient treatments. In comparison to the aerial traits, there was less difference between LowN and LowP for root features, and there was evidence of a partially additive effect in the combined LowNP treatment (Fig. S3; MZ66_Giaroots_Analysis in Supplemental File 1. e.g. network volume - KW adj. $p=0.009$; Dunn test at $\alpha=$ 0.05 . Full: $19.40 \pm 1.68$ a; LowP: $12.43 \pm 1.89 \mathrm{ab}$; LowN: $10.10 \pm 1.92 \mathrm{bc}$; LowNP: $7.23 \pm 1.71 \mathrm{c}$ ).

\section{The leaf ionome was modified under low $\mathrm{N}$ and $\mathrm{P}$ treatments}

We quantified the total concentration of twenty different elements in the leaf tissue using inductively coupled plasma mass spectrometry (ICP-MS). The protocol used did not allow determination of $\mathrm{N}$ concentration. We detected a significant (ANOVA adj. $p<0.05$ ) effect of treatment on the concentration of ten of the elements quantified (Fig. 2e, S4; MZ66_Ionomics_Analysis in Supplemental File 1). We observed both decreases and increases in concentration for different elements, indicating that the effects could not be explained solely based on changes in root:shoot ratio. In line with previous studies $[15,28,46]$, we observed an increase $(1.8$ fold) in leaf total $\mathrm{P}$ concentration of plants grown under LowN compared with Full (P concentration - ANOVA adj. $p<0.001$; Tukey test at $\alpha=0.05$. LowN: $3543 \mathrm{ppm} \pm$ 110a; Full: $1983 \mathrm{ppm} \pm 96 \mathrm{~b}$; LowNP: 1174 ppm $\pm 98 \mathrm{c}$; LowP: $734 \mathrm{ppm} \pm 108 \mathrm{~d}$ ). Unsurprisingly, total P concentration was lower under LowP (734 ppm). More remarkably, total $\mathrm{P}$ concentration was higher under LowNP (1174 ppm) than in LowP, although we note that LowNP plants were also smaller than those under LowP. We also saw a significant increase in $\mathrm{Ni}$ concentration under LowN and increases in $\mathrm{K}$ and $\mathrm{Rb}$ concentration under LowP (Fig. 2e, S4; MZ66_Ionomics_Analysis in Supplemental File 1).

\section{The transcriptional response to $\mathrm{P}$ starvation is repressed under $\mathbf{N}$ limitation}

Based on our initial characterization, we selected 25 DAE - the point at which we first saw a significant treatment effect on growth across leaves (Fig. 1) - for transcriptional profiling. We grew a second set of plants under the same nutrient conditions as used previously, harvesting total roots and pooled leaf blades at $25 \mathrm{DAE}$ from two individuals per treatment for RNA extraction and sequencing. Sequencing reads were aligned to the maize (var. B73, ref-gen V3) transcript set and collapsed at the gene level to obtain read count data. We analyzed count data from all treatments and both tissues in a single linear model to identify significant effects of LowN, LowP or their interaction on gene expression. A total of 1555 genes were identified to be N/P regulated (false discovery rate $[\mathrm{FDR}]$ nutrient terms $<0.01 ; \mid \log _{2}$ fold change $[\mathrm{LFC}] \mid>1$ for at least one nutrient-associated model term; MZ67_DEG_set in Supplemental File 2). Regulated genes were further classified as upregulated or downregulated in different tissue/treatment combinations by the sign and magnitude $(|\mathrm{LFC}|>1)$ of pairwise differences with respect to the Full treatment in the relevant tissue (MZ67_DEG_set in Supplemental File 2).

A similar number of genes were upregulated as were downregulated; a greater number of regulated genes were detected in leaves than roots (Fig. 3a-d). We compared the transcriptional response to the treatments by tissue and sign of the effect (up or down). There was little overlap between the responses to LowN and LowP single stress treatments (Fig. 3a-d. e.g. of a combined total of 737 genes upregulated in the leaf between LowN and LowP, only 30 were shared). When presented with the combined LowNP treatment, plants broadly followed the LowN response pattern: most regulated genes were shared between LowN and lowNP; very few genes that were regulated under LowP showed similar regulation under lowNP (Fig. 3a-d). This trend was evident in both leaves and roots, and among both up- and down- regulated genes.

Our model included an NxP interaction term. Although our power to detect interaction effects was no doubt limited by the level of replication, we were able to identify $81 \mathrm{NxP}$ interaction genes (FDR NxP terms < $0.05 ;|L F C|>1$ for at least one nutrient interaction model term. MZ67_NxP_set in Supplemental File 2), i.e. genes regulated by the availability of one nutrient in a manner conditional on the availability of the second. We explored the distribution of these 81 genes across the sets of upregulated and downregulated genes (pairwise $|\mathrm{LFC}|>1$ ) from the different treatments and tissues (Fig. $3 e$ ). The majority (74 of 81 ) of $\mathrm{NxP}$ genes were upregulated in the LowP single treatment in leaves (Fig. 3e; MZ67_NxP_set in Supplemental File 2). Only 5 of these 74 leaf LowP induced NxP genes were also upregulated under LowNP. Furthermore, 35 and 25 of these 74 were downregulated in the leaves under LowN and LowNP, respectively (Fig. 3e; MZ67_NxP_set in Supplemental File 2). A similar pattern was seen in roots - 60 of the 81 $\mathrm{NxP}$ genes were upregulated in roots under LowP, 55 in common with the leaves; none of the $81 \mathrm{NxP}$ genes were upregulated in the roots under lowN or lowNP; ten and 9 root LowP induced $\mathrm{NxP}$ genes were downregulated in roots under LowN and LowNP, respectively (MZ67 NxP_set in Supplemental File 2). These observations suggested that the responses to LowP and LowN were not only distinct, but antagonistic, and that under LowNP the pattern seen under LowN dominated. Although NxP interaction was not supported statistically beyond these 81 candidates at the single gene level, a similar global pattern was seen across the complete 1555 


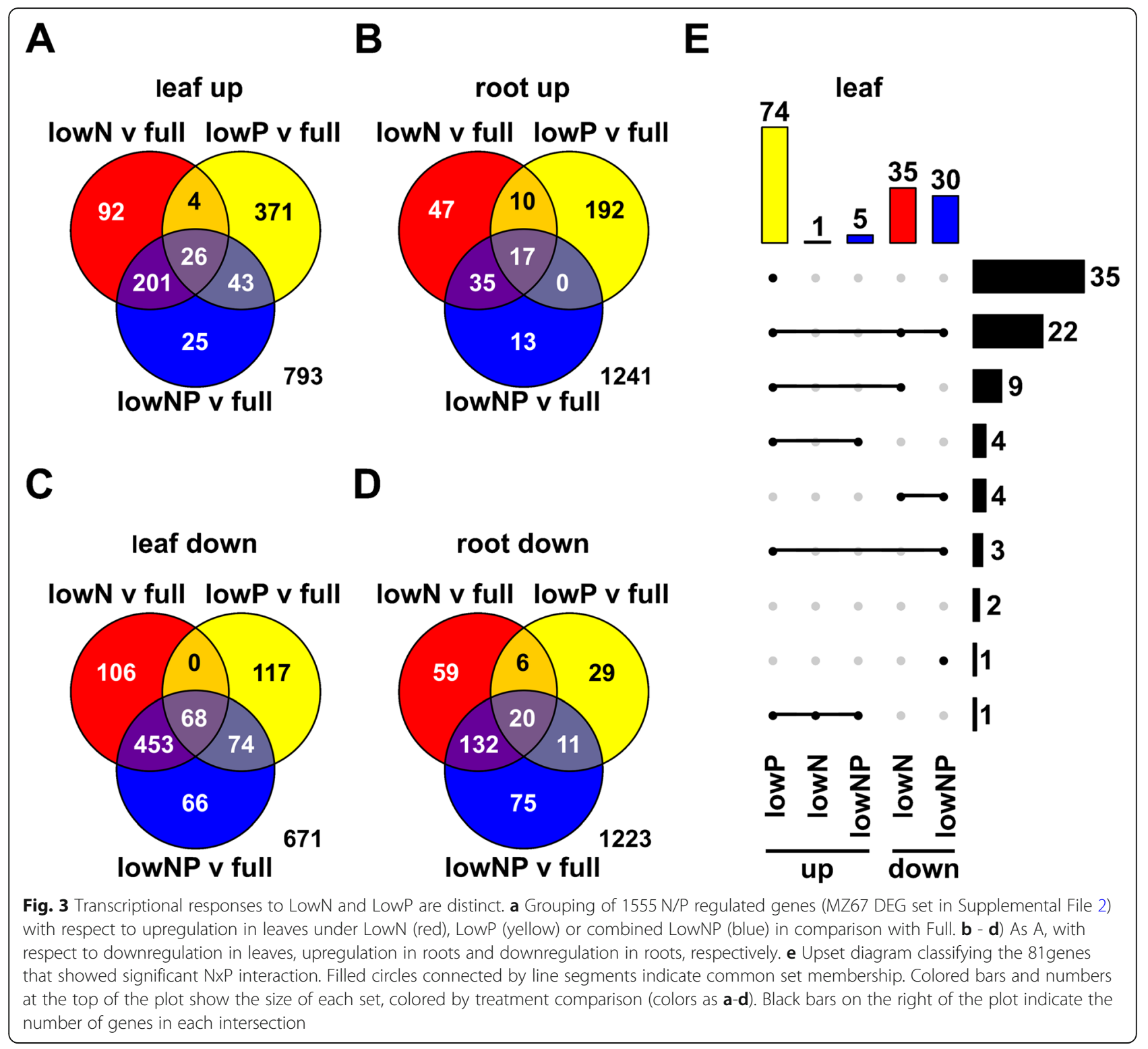

gene set. Of 444 genes up-regulated in leaves under LowP (pairwise LFC >1), only 30 were up-regulated under LowN, while 178 were down-regulated (Fig. 4a; MZ67_DEG_set in Supplemental File 2). Similarly, of these 444, only 69 were up-regulated under combined LowNP, with 121 down-regulated (Fig. 4a, S5A-B, MZ67_DEG_set in Supplemental File 2).

To gain insight into the functional consequences of the transcriptional responses, we examined "classical genes" (a curated set of $\sim 5000$ well-annotated genes, many linked with existing functional data: maizegdb.org/gene_center/ gene) in our regulated gene set. We supplemented the classical set with a number of additional annotations [56, 57] based on identification of maize orthologs of highinterest candidate genes, notably members of the maize SPX-domain and PAP gene families (Fig. S5C [58]). The
SPX-domain family proteins have been clearly linked with crosstalk in N-P signaling in Arabidopsis and rice [42, 44, 50], but the family has not been previously annotated in maize. We therefore identified the complete set of SPXdomain protein encoding genes from maize and assigned a nomenclature based on phylogenic analysis that we use below (Fig. S6; MZ67_Spx_Genes in Supplemental File 2). The behavior of the top thirty (ranked by FDR) regulated classical genes mirrored the global trend - namely, strong induction under LowP that was absent, or shifted to repression, in LowN or LowNP (Fig. S5C). The top classical genes encoded functions previously associated with the PSR [59-62], including PHT1 high-affinity phosphate transporters, PAPs, lipid-remodeling enzymes and members of the SPX domain family (Figs. S5C, S6). We further examined functional patterns using Gene Ontology (GO) 


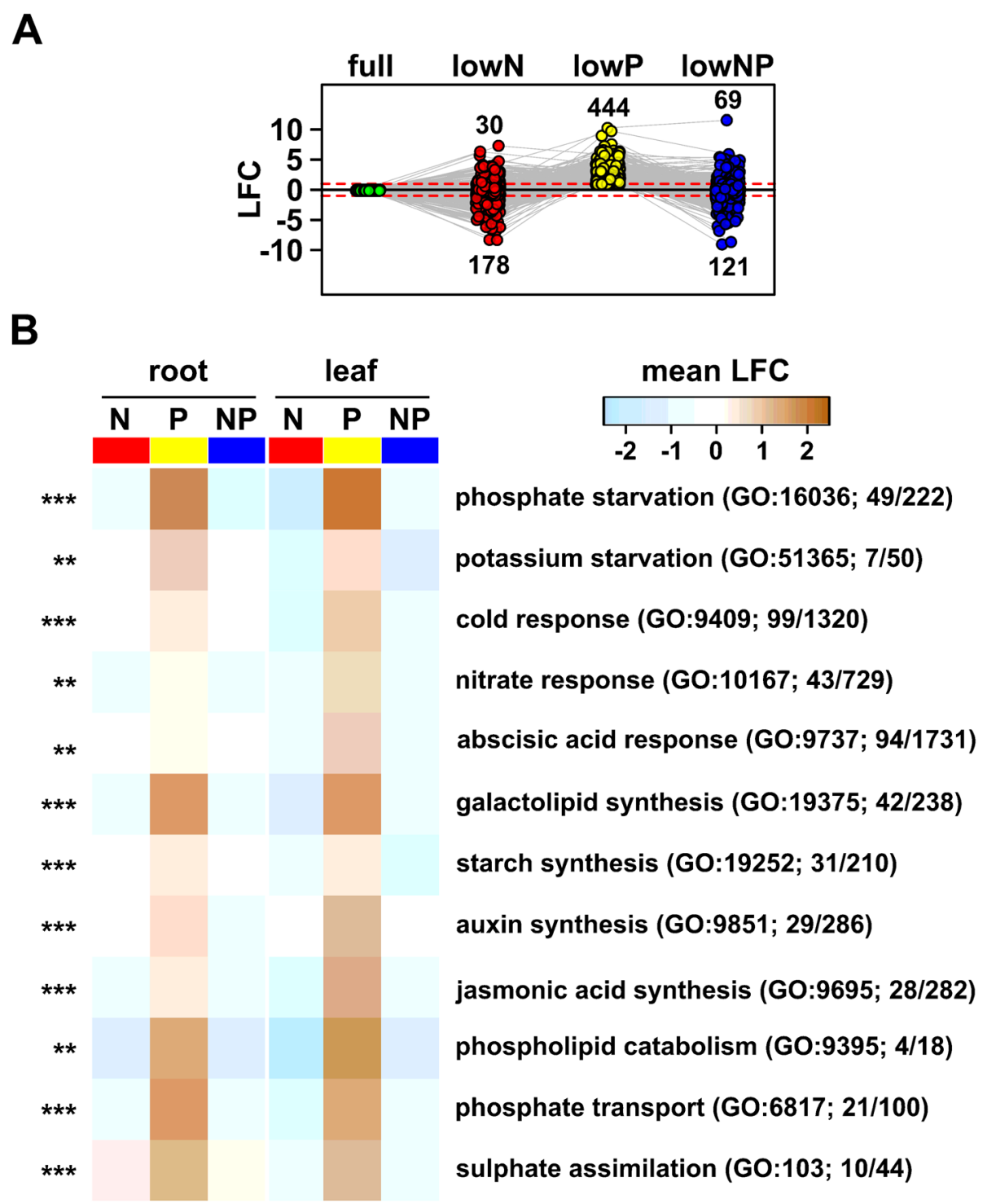

Fig. 4 Transcript induction under LowP is repressed by LowN. a Reaction norm plot of differential transcript accumulation (log 2 fold change, LFC) for 444 genes induced by lowP in the leaf with respect to Full (green) under LowN (red), LowP (yellow) and combined LowNP (blue). Numbers indicate the count of genes above/below the $+/-1$ LFC threshold. $\mathbf{b}$ Heat map showing the mean LFC in each treatment of genes associated with selected GO terms enriched in the 1555 gene set (Supplemental File 2). LFC calculated with respect to Full, separately for roots and leaves. GO term names are abbreviated. GO term identifiers are given in parentheses along with the number of genes assigned in the test set over the total number in the GO term. The significance of GO term enrichment is indicated to the left of the heat map as ${ }^{* * *} p<0.001,{ }^{* *} p<0.01$, * $p<0.05$

analysis of the complete 1555 regulated gene set (MZ67 GO_Analysis in Supplemental File 2). We calculated the mean LFC with respect to Full of the regulated genes belonging to each enriched GO set under the three nutrient treatments, in roots and leaves (Fig. 4b; MZ67_GO_Analysis in Supplemental File 2). As for the single gene analysis, we observed a signature of upregulation under LowP associated with downregulation under LowN. Of the top $50 \mathrm{GO}$ sets by $p$ value for enrichment, the mean LFC under LowP was positive for 46 sets in roots and for all 50 in the leaves; for the same sets the mean LFC was negative in all but two cases in LowN and LowNP treatments, in both roots and leaves (MZ67_GO_Analysis in Supplemental File 2). This pattern extended from the general cellular response to phosphate starvation term (GO: 16036) to specific processes such as synthesis of galactolipids (GO: 19375) and the hormones auxin (GO: 9851) and jasmonic acid (GO: 9695; Fig. 4b). 


\section{Mild N stress is sufficient to repress the $\mathrm{P}$ starvation response}

Although LowN and LowP treatments were adjusted to 9 and 3\% of the Full concentration, respectively, it was evident by 40 DAE that the LowN treatment produced a greater limitation on growth than LowP. As such, we speculated that the dominance of the LowN transcriptional response under the combined NP treatment was simply a consequence of the greater severity of the LowN stress. To address this hypothesis, we grew an additional set of plants under high and low P (P5 and $\mathrm{P} 1$, respectively; our original Full and LowP levels) in combination with five different levels of $\mathrm{N}$ (N5 to N1, high to low; the extremes corresponding to our previous Full nutrient and LowN treatments). As for our whole transcriptome experiment, we harvested plants at 25 DAE (Fig. 1). We measured shoot and root fresh weight and again saw that the single stress combination N1P5 reduced growth more than the complementary N5P1 treatment (Fig. 5a, b). At intermediate $\mathrm{N}$ availability, however, we could observe different combinations of $\mathrm{N}$ and $\mathrm{P}$ with equivalent growth: e.g., N4P5 was indistinguishable from N5P1 in terms of shoot fresh weight. To evaluate the impact of $\mathrm{N}$ availability on the PSR, we used real-time PCR to quantify the expression of a panel of selected genes. We first assayed the well-characterized $\mathrm{N}$ responsive genes Nir-a (GRMZM2G079381) and Npf6.6 (GRMZM2G161459), encoding a nitrite reductase and a nitrate/peptide transporter $[23,63]$, respectively, to confirm the impact of the $\mathrm{N}$ treatments. As previously shown and as observed in our transcriptome data (MZ67_DEG_set in Supplemental File S2), Nir-a and Npf6.6 were down-regulated in reduced $\mathrm{N}$ treatments (Nir- $a$ is expressed predominantly in leaf tissue. Figure 5c, d; MZ95_DE_analysis in Supplemental File S3). The accumulation of Nir- $a$ and Npf6.6 decreased from N5 to N1 treatments, indicating a progressive impact on plant $\mathrm{N}$ status and signaling (Fig. 5c, d). Interestingly, expression of Npf6.6 was also induced in the roots under $\mathrm{P} 1$, this response being most pronounced at N5. We then assayed four PSR genes, selected based on previous reports and our transcriptome data: Pht1;9, Pht1:13 phosphate transporter genes in roots [27], the $M f_{s} 2$ $S P X$-family gene in leaves, and the Pap10 purple acid phosphatase gene in both roots and leaves [58]. All four PSR genes were strongly induced by P1 under N5 conditions (Fig. 5c-d; $M f_{s} 2$ 1.8-fold increase N5P1/N5P5 in leaves; Pap10 1.85-fold increase N5P1/N5P5 in leaves, 4.93-fold increase in roots; Pht1;9 4.33-fold increase N5P1/N5P5 in roots; Pht1:13 4.82-fold increase N5P1/ N5P5 in roots). However, once $\mathrm{N}$ availability was reduced to N4, the level of PSR transcript accumulation under P1 was reduced (Fig. 5c, d; MZ95_DE_analysis in Supplemental File S3). At N3 and below, P1 induction of
PSR genes was absent. Interestingly, $M f_{s} 2$ and Pap10 showed a level of constitutive expression in leaves under $\mathrm{N} 5 \mathrm{P} 5$ conditions that was reduced by $\mathrm{N}$ limitation $(M f s 2$ 2.10- and 14.72- fold reduction in N4P5 and N1P5, respectively; Pap10 4.94- and 19.70- fold reduction in N4P5 and N1P5, respectively; Fig. 5c-d; MZ95_DE_analysis in Supplemental File S3).

\section{$\mathrm{P}$ concentration in the leaves responds to both $\mathrm{P}$ and $\mathrm{N}$ availability in the substrate}

Previous studies and our observations at 40 DAE showed an increase in total $\mathrm{P}$ concentration in the leaves of young plants grown under $\mathrm{N}$ limitation [15, 28, 46]. As such, the antagonism observed between transcriptional responses to our LowN and LowP treatments might be driven by downregulation of PSR genes in response to higher cellular $\mathrm{P}$ concentration. To investigate this possibility, we quantified total P concentration using ICP-MS in the roots and leaves of the plants in our N-dose experiment (MZ95_Ion_Concentration_Analysis in Supplemental Table S3). We again observed an increase in total $\mathrm{P}$ concentration in both leaves and roots as $\mathrm{N}$ was reduced, in either P1 or P5 (Fig. 6a). However, the increase over the N5-N3 range was minimal (P concentration root. Tukey test at $\alpha=0.05$. N5P5: $1035 \mathrm{ppm} \pm$ 100ab; N3P5: 1082 ppm $\pm 82 \mathrm{ab} ;$ N5P1: 809 ppm $\pm 32 \mathrm{~b}$; N3P1: 1139 ppm $\pm 55 \mathrm{ab}$; P concentration leaf. Tukey test at $\alpha=0.05$. N5P5: $2525 \mathrm{ppm} \pm 103 \mathrm{efg}$; N3P: $3545 \mathrm{ppm} \pm$ 203abc; N5P1: 2064 ppm \pm 81 g; N3P1: 2277 ppm \pm 86 fg), suggesting that total $\mathrm{P}$ concentration does not explain the strong effects on gene expression we saw over the same range.

\section{Discussion}

To explore the interaction between $\mathrm{N}$ and $\mathrm{P}$ signaling pathways in maize, we characterized transcriptional responses in roots and leaves to low $\mathrm{N}$, low $\mathrm{P}$ and combined low NP stress. We observed responses to our LowN and LowP treatments to be distinct and antagonistic. Furthermore, under combined LowNP, the LowN pattern dominated and the classic PSR was absent, even though plant growth was partially P limited (as determined by phenotypic comparison to plants grown under the single LowN stress). Although there were differences at the level of individual genes, our LowN and LowP single stress results are in broad agreement with a previous report in which a similar antagonism was observed, and many classic PSR genes were seen to be down-regulated under LowN [15]. The potential adaptive value of such antagonism is not clear.

$\mathrm{N}$ is typically found deeper in the soil than $\mathrm{P}$, reflecting differences in mobility. Consequently, a root system optimized to access $\mathrm{P}$ in the topsoil will be less suited to $\mathrm{N}$ acquisition, and vice versa [64-66]. In addition, the 


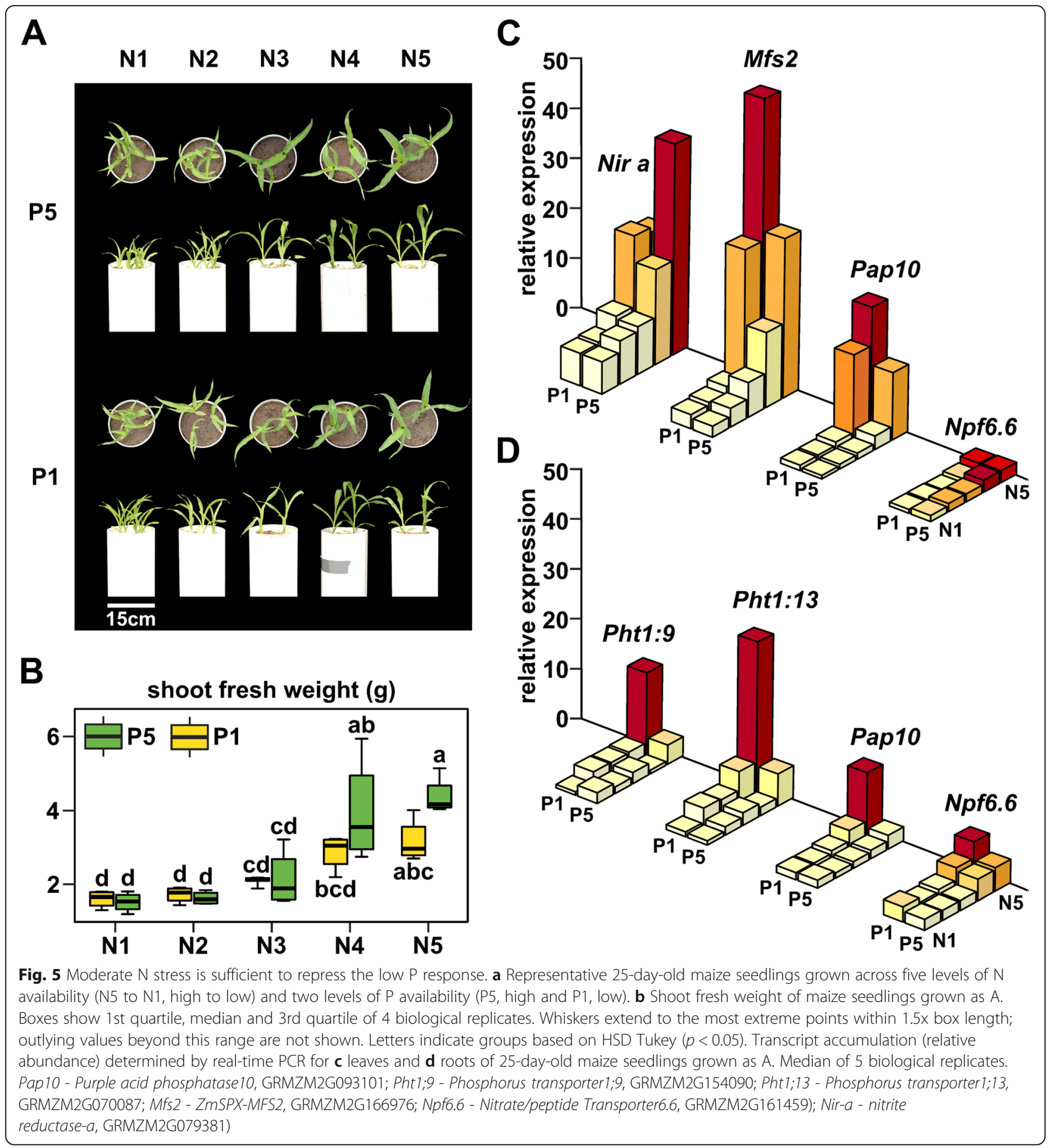

optimal pattern of root branching and root length is different for acquisition of $\mathrm{N}$ or $\mathrm{P}$ [64-66]. We did not detect dramatic differences in RSA between LowN and LowP treatments at $40 \mathrm{DAE}$, although the growth system, the relatively young age of the plants, and the severity of stress may have limited the expression of potential root developmental responses. Nonetheless, the antagonistic regulation of genes associated with hormone signaling (e.g., genes belonging to $\mathrm{GO}$ terms GO:9851 auxin biosynthetic process, GO:9695 jasmonic acid biosynthetic process; GO:9735 response to cytokinin) may mirror the differing demands placed on plant architecture by $\mathrm{N}$ and $\mathrm{P}$ limitation.

Once acquired, the efficiency of internal P use can be maximized by remobilization to the part of the plant where need is greatest over the growing season $[3,4]$. 


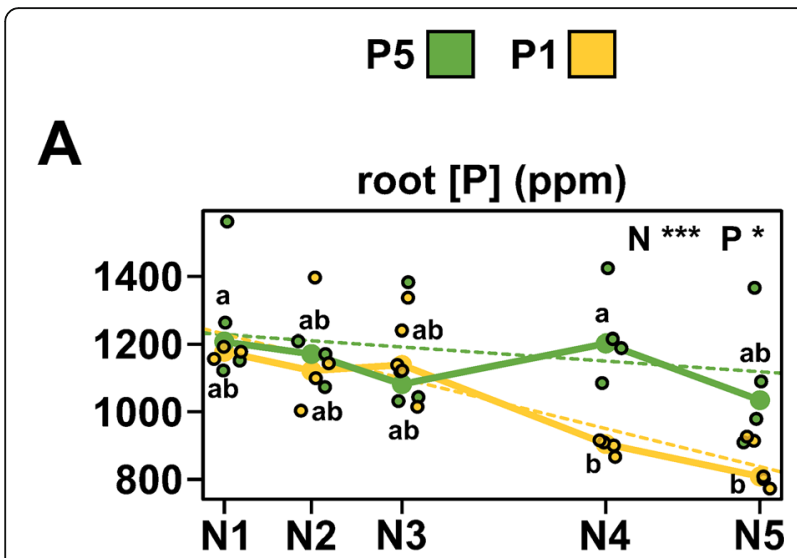

B

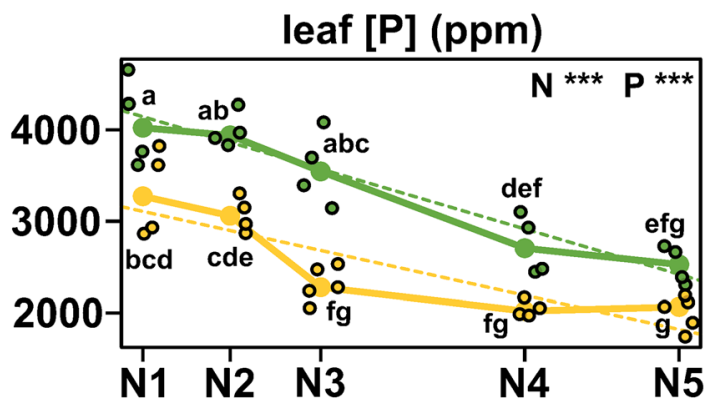

Fig. $\mathbf{C} \mathrm{P}$ accumulation responds to $\mathrm{P}$ and $\mathrm{N}$ availability. $\mathbf{a}$ root and $\mathbf{b}$ leaf $\mathrm{P}$ concentration (ppm dry mass) of 25-day-old maize seedlings grown across five levels of $\mathrm{N}$ availability (N5 to N1, high to low) and high (green points and trace) and low (yellow points and trace) levels of $\mathrm{P}$ availability. Large points show treatment medians; small points show individual (4) biological replicates. Dashed lines show best fit from a multiple regression model. Asterisks represent statistical significance of model terms ( $p$ value $\leq 0.001 * * * 0.001-0.01$ $* * ; 0.01-0.05 *$ ). N, P main effect of $N$ and $P$, respectively. NP, NxP interaction term. Lowercase letters indicate significant $(p<0.05)$ pairwise differences (Tukey)

PAPs remobilize $\mathrm{P}$ by releasing inorganic $\mathrm{P}$ from organic compounds. Induction of PAP encoding genes and increased PAP activity is a classic component of the PSR across the tree of life, including Arabidopsis [67, 68], rice [69] and maize [58]. We observed several Pap genes to be upregulated under LowP in both roots and leaves. In addition to remobilizing $\mathrm{P}$ within the plant, PAPs are also secreted to the rhizosphere, enhancing the availability of inorganic P for uptake $[67,68]$. Pap10 was one of the most strongly regulated genes in our analysis. Reflecting the global pattern, Pap10 was strongly induced by LowP, but only in N4-N5 conditions. Furthermore, Pap10 showed a constitutive level of expression in our Full nutrient condition that was reduced by lowering $\mathrm{N}$ availability. Genes linked to lipid remodeling - the replacement of membrane phospholipids by galactolipids or sulfolipids under P starvation $[4,70,71]$ - followed a similar trend. Downregulation of constitutively expressed PSR-associated genes by single low $\mathrm{N}$ treatments has been previously reported in four commercial maize hybrids and two maize inbred lines [28, 32, 72]. One study that did not report such downregulation of PSR genes also found no evidence of the downregulation of $\mathrm{N}$ assimilation genes typically associated with $\mathrm{N}$ starvation, indicating that the precise nature and timing of the treatment are important [73]. A similar downregulation of PSR genes occurs in rice under prolonged $\mathrm{N}$ starvation [50], but not within the first $12 \mathrm{~h}$ of shift to $\mathrm{N}$ starvation conditions [5], although a low $\mathrm{N}$ metabolic response can occur as early as $1 \mathrm{~h}$ after such a shift [74]. Our observations that the negative impact of low $\mathrm{N}$ availability on PSR gene expression dominates in the combined LowNP treatment implies that, under this dual stress, maize plants are failing to activate welldefined aspects of the PSR, such as P remobilization or lipid remodeling. In the future, it will be informative to assay PAP activity and lipid composition at low $\mathrm{N}$ and low $\mathrm{P}$ availability.

Our study confirmed previous observations of $\mathrm{P}$ hyper-accumulation in maize leaves under $\mathrm{N}$ limitation $[15,28]$, an effect also reported in rice and Arabidopsis [42, 75]. Initially, we considered the hypothesis that down-regulation of PSR genes in LowN was a secondary response to an increase in total internal $\mathrm{P}$ concentration. However, LowNP conditions downregulated PSR genes even when low $\mathrm{P}$ availability prevented accumulation of total $\mathrm{P}$ to the concentration seen under LowN conditions. Significantly, mild N limitation (N4) was sufficient to suppress induction of PSR genes under LowP with no change in internal total $\mathrm{P}$ concentrations. Plants perceived $\mathrm{N}$ reduction from $\mathrm{N} 4$ and below, as demonstrated by the reduced accumulation of Nir- $a$ transcripts, a well characterized marker of plant $\mathrm{N}$ status [76]. Overall, our data support an $\mathrm{N}$-mediated impact on PSR via modified signaling or P partitioning, rather than as the secondary effects of total internal $\mathrm{P}$ hyper-accumulation.

Currently, it is difficult to reconcile PSR repression and $\mathrm{P}$ hyper-accumulation. It would be informative to examine earlier stages of plant growth for evidence of a transient induction of PHT1 transporter encoding genes under LowN, although no such signal has been previously reported in comparable experiments in maize or other plants, nor in experiments using a transfer from replete to $\mathrm{N}$ starvation conditions [74]. PHT1 transporters are subject to regulation at the post-translation level $[45,77,78]$ and measurement of protein levels and localization would provide a fuller picture, as would quantification of root $\mathrm{P}$ permeability and $\mathrm{P}$ uptake. In rice, it has been reported that the roots of plants grown under $\mathrm{N}$ starvation show increased permeability to inorganic P [46]. The balance between $\mathrm{P}$ concentration in the leaves and $\mathrm{P}$ uptake by the roots is maintained by 
systemic signaling through the mobile microRNA miR399 [79, 80]. As P becomes limiting in the shoots, miR399 is produced and travels to the roots to target transcripts encoding the PHOSPHATE2 (PHO2) E2 ubiquitin conjugase, in turn promoting accumulation of PHT1 transporters [81-83]. Previous reports have shown that miR399 expression in maize can increase in $\mathrm{N}$ starvation, although the effect depends on both the nature of the $\mathrm{N}$ treatment and the length of exposure $[84,85]$.

Study of NP crosstalk in Arabidopsis and rice has highlighted the importance of the SPX protein family. Although first described as regulators of $\mathrm{P}$ homeostasis [86], SPX and SPX-RING proteins have subsequently been linked with $\mathrm{N}$ signaling $[42,44,50]$. We identified 15 SPX-domain family genes in maize, the same as in rice, grouped into the four previously reported classes (SPX, SPX-EXS, SPX-MFS and SPX-RING [87]). N and P availability regulated transcript levels across the SPX family, consistent with a role in the integration of $\mathrm{N}$ and $\mathrm{P}$ signaling pathways (Fig. S6). Transcripts encoding members of the single SPX domain class responded positively to LowP in both roots and leaves, as has been seen previously in Arabidopsis and rice [88, 89]. In rice, over-expression of OsSPX1 and OsSPX6 suppresses the PSR, suggesting that they may act in a negative-feedback loop. Conversely, under-expression of OsSPX1 and OsSPX6 leads to increased P accumulation through upregulation of genes involved in $\mathrm{P}$ uptake $[89,90]$. The rice SPX4 protein exerts a further negative control on the PSR by sequestering the MYB transcription factor PHR2 in the cytosol, preventing its translocation into the nucleus and activation of target genes [49]. Under P starvation, SPX4 is degraded, freeing PHR2 to activate the PSR. It has recently been reported that SPX4 turnover in rice requires the activity of the NRT1.1b [50]. Given that the abundance of NRT1.1b itself is N responsive, the NRT1-SPX4 module represents a point of integration between $\mathrm{N}$ and $\mathrm{P}$ signaling pathways.

Hyperaccumulation of $\mathrm{P}$ under $\mathrm{N}$ limitation indicates an uncoupling of $\mathrm{P}$ uptake from leaf $\mathrm{P}$ concentration [81-83]. Similar uncoupling occurs in Arabidopsis mutants under-expressing the SPX-EXS gene PHO1, in parallel with changes in subcellular partitioning of $P$ between vacuolar stores and the cytosol [91]. The maize genome encodes two co-orthologs of the Arabidopsis PHO1 - maize Pho1;2a and Pho1;2b [92]. We found both Pho1;2a and Pho1;2b to show evidence of downregulation under LowN, potentially contributing to changes in $\mathrm{P}$ partitioning. While our observations suggest that changes in total internal P concentration cannot explain the observed effect of $\mathrm{N}$ limitation on the PSR, we do not have data on the level of $\mathrm{P}$ in the cytosol itself. A second group of SPX proteins, the SPX-MFS proteins, plays a more direct role in regulating cytosolic $\mathrm{P}$ concentration by mediating $P$ influx into the vacuole $[93,94]$. Under P starvation, OsSPX-MFS1 and OSSPS-MFS3 are down regulated, consistent with retaining more of the total internal P pool in the cytosol for direct use [84]. In contrast, OsSPX-MFS2 is upregulated under P starvation, and may be acting differently $[95,96]$. The MFS2 protein was not identified in a screen for vacuolar P efflux transporters [94], suggesting that it is not simply working antagonistically to MFS1 and MFS3. In maize, we found both $M f s 1$ and $M f s 3$ to be encoded by two genes, with both paralogs of each pair down regulated under LowP in the leaves, indicating a similar function to the rice genes. $M f_{s} 2$ was found to be a single copy gene in maize, and, as in rice, to be upregulated under LowP. It will be informative to functionally characterize the link between the maize SPX-domain proteins and N-P signaling.

\section{Conclusions}

A reduction in $\mathrm{N}$ availability suppresses the PSR in young maize plants. Somewhat paradoxically, low N availability also results in an increase in internal $\mathrm{P}$ concentration, although not to levels that might explain the repression of low $\mathrm{P}$ responsive genes. In cultivated fields, $\mathrm{P}$ limitation may coincide with low $\mathrm{N}$ availability. As such, maize may grow without the classical low P response of model systems, making us rethink our current understanding of acclimation to $\mathrm{P}$ starvation. Further work is needed to evaluate the nature of the transcriptional PSR in maize under cultivation. We might also consider the merits of biotechnological manipulation to enhance low $\mathrm{P}$ responses under low $\mathrm{N}$ conditions.

\section{Methods}

\section{Plant material and growth conditions}

Plants in this study were maize (Zea mays ssp. mays var. W22) wild-type segregants from a larger population segregating for the Zmpho1;2-m1.1' mutation, generated from the stock bti31094::Ac [92]. The original bti31094:: $A c$ stock is available from the Maize Genetics Cooperation Stock Center. Genotypic analysis of the segregating population was as described previously [92]. Samples from individuals carrying the Zmpho1;2-m1.1' mutation were retained for future analysis. Plants were grown in the greenhouse in sand substrate with nutrient conditions maintained by a combination of fertilization with Hoagland solution [97]; $5 \mathrm{mM} \mathrm{KNO}_{3}, 0.25 \mathrm{mM} \mathrm{Ca}$ $\left(\mathrm{NO}_{3}\right)_{2}, \quad 2 \mathrm{mM} \quad \mathrm{MgSO}_{4}, \quad 1 \mathrm{mM} \quad \mathrm{KH}_{2} \mathrm{PO}_{4}, \quad 20 \mu \mathrm{M}$ $\mathrm{FeC}_{6} \mathrm{H}_{6} \mathrm{O}_{7}, 9 \mu \mathrm{M} \mathrm{MnSO}_{4}, 1.2 \mu \mathrm{M} \mathrm{ZnSO}_{4}, 0.5 \mu \mathrm{M} \mathrm{CuSO}_{4}$, $\left.10 \mu \mathrm{M} \mathrm{Na}_{2} \mathrm{~B}_{4} \mathrm{O}_{7}, 0.008 \mu \mathrm{M}\left(\mathrm{NH}_{4}\right) 6 \mathrm{Mo}_{7} \mathrm{O}_{24}\right)$, modified as described below and, where stated, by addition of $1.5 \%$ $(\mathrm{v} / \mathrm{v})$ of P-charged acidified alumina [98]. Hoagland $\mathrm{N}$ concentration was adjusted by substitution of $\mathrm{KNO}_{3}$ with $\mathrm{KCl}$ and $\mathrm{CaCl}_{2}[99,100]$. Hoagland solution was 
applied at $1 / 3$ strength with the final $\mathrm{N}$ and $\mathrm{P}$ concentrations used in different experiments as stated below.

For growth to 40 days after emergence (DAE), 35 plants were evaluated in PVC tubes $(15 \mathrm{~cm}$ diameter; 1 $\mathrm{m}$ tall), planted in 4 groups, at intervals of 1 week. Tubes were filled with $\sim 17 \mathrm{l}$ of washed sand. In the upper third of the tube, soil was mixed with $1.5 \%$ solid-phase $\mathrm{P}$ buffer (alumina-P) [98] loaded with $209 \mu \mathrm{M} \mathrm{KH}_{2} \mathrm{PO}_{4}$ for Full treatments and $11 \mu \mathrm{M} \mathrm{KH}_{2} \mathrm{PO}_{4}$ for LowP treatments. Four imbibed seeds were planted at $4 \mathrm{~cm}$ depth per tube, thinned to a single plant a week after emergence. Plants were irrigated with distilled water up until 10 DAE after which Hoagland treatments were applied as a $1 / 3$ strength solution, at a rate of $200 \mathrm{ml}$ every third day, with final concentration: Full $1750 \mu \mathrm{M} \mathrm{NO}_{3}{ }^{2}$; LowN

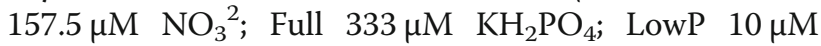
$\mathrm{KH}_{2} \mathrm{PO}_{4}$. During the growth period, plants were evaluated by non-destructive measurement of stem width, stem height, leaf number, and length and width of each fully expanded leaf. Stem height was measured from the soil to the last developed leaf collar. Measurements were collected every fifth day from 10 DAE. At 40 DAE, plants were removed from the tubes, minimizing damage to the root system, washed in distilled water and dried with paper towels before measuring root and shoot fresh weight. The cleaned root system was placed in a waterfilled tub and photographed using a digital Nikon camera D3000. Raw images were individually processed using Adobe Photoshop CC (Version 14.0) to remove the background and obtain a good contrast between foreground and background non- root pixels. Processed images were scaled and analyzed using GiA Roots software [55]. Roots and shoots were placed in an oven at $42{ }^{\circ} \mathrm{C}$ for a week before measuring dry weight and collecting samples for ionomic analysis (see below). The complete set of measurements collected is described in MZ66_Raw_Data in Supplemental File 1.

For growth up to $25 \mathrm{DAE}$, plants were grown in smaller PVC tubes $(15 \mathrm{~cm}$ diameter, $50 \mathrm{~cm}$ tall). For the RNA-seq analysis, the top $30 \mathrm{~cm}$ of the $50 \mathrm{~cm}$ tube included $1.5 \%$ solid-phase $\mathrm{P}$ buffer (alumina-P [98]). The whole plant was harvested, separating the stem and leaves, a segment $2 \mathrm{~cm}$ above and below the crown roots and the remaining root system. Tissue was immediately frozen in liquid nitrogen and stored at $-80^{\circ} \mathrm{C}$. Samples were homogenized with cooled pestle and mortar and aliquoted under liquid nitrogen for transcriptome analysis. For the $\mathrm{N}$-dose experiment, plants grown in $50 \mathrm{~cm}$ tubes were irrigated with combinations of $\mathrm{P}$ at 10 or $333 \mu \mathrm{M}$ (P1, P5; solidphase $\mathrm{P}$ buffer was not used in this experiment), and $\mathrm{N}$ at $157.5,233,350,875$ or $1750 \mu \mathrm{M}$ (N1 to N5). Leaf and root tissue were collected at 25 DAE for gene expression and ionomic analysis.

\section{Determination of elemental concentration by ICP-MS analysis}

Ion concentration was determined as described previously by [101]. Briefly, root and shoot samples were analyzed by inductively coupled plasma mass spectrometry (ICP-MS) to determine the concentration of twenty metal ions. Weighed tissue samples were digested in 2.5 $\mathrm{mL}$ concentrated nitric acid (AR Select Grade, VWR) with an added internal standard (20 ppb In, BDH Aristar Plus). Concentration of the elements $\mathrm{Al}, \mathrm{As}, \mathrm{B}, \mathrm{Ca}, \mathrm{Cd}$, $\mathrm{Co}, \mathrm{Cu}, \mathrm{Fe}, \mathrm{K}, \mathrm{Mg}, \mathrm{Mn}, \mathrm{Mo}, \mathrm{Na}, \mathrm{Ni}, \mathrm{P}, \mathrm{Rb}, \mathrm{S}, \mathrm{Se}, \mathrm{Sr}$ and Zn was measured using an Elan 6000 DRC-e mass spectrometer (Perkin-Elmer SCIEX) connected to a PFA microflow nebulizer (Elemental Scientific) and Apex HF desolvator (Elemental Scientific). A control solution was run every tenth sample to correct for machine drift both during a single run and between runs.

\section{Statistical analysis of plant growth and ionomic data}

For plants grown to $40 \mathrm{DAE}$, traits were obtained from 34 individuals (one individual was removed as a clear outlier with poor growth). Individuals were distributed across nutrient treatments as: Full, $n=7$; LowN, $n=5$; LowP, $n=9$; LowNP, $n=13$, across 4 planting dates. Traits included direct measurements and derived values (e.g., total leaf surface area or biomass totals). Nondestructive measurements were repeated at 5-day intervals during the experiment. Destructive measurements were made for all 34 individuals at harvest. The data set include element concentrations determined by ICP-MS and root architectural traits extracted by image analysis, as described above. The dataset and analysis are presented in Supplemental File 1.

All statistical analysis was performed in R [102]. Full, LowN, LowP and LowNP were treated as four levels of a single treatment factor. For growth and endpoint data and GiaRoots features, we used R/stats::kruskal-test to assess the treatment effect on each trait with a nonparametric Kruskal-Wallis test. Element concentration was analyzed using ANOVA. In all cases, $p$-values were adjusted for multiple testing using the Bonferroni method with R/stats::p.adjust, applied separately to growth, endpoint, GiaRoots and element data sets. Where the treatment effect was significant (adjusted $p<$ 0.05 ), we applied a pairwise post hoc test to identify differences between treatments: Dunnett test (R/dunn.test:: dunn.test [103]) for growth, endpoint and GiaRoots features and Tukey HSD for element data (R/agricolae:: HSD.test [104]). For Dunnett test results, letters were assigned to means groups using R/multcompView::multcompLetters [105]. For visualization, we used R/stats::Im to fit the model trait value $\sim 0+$ treatment + planting date + error, extracting model coefficients and standard errors for plotting. 
RNA-sequencing analysis of differential gene expression RNA-sequencing analysis was carried out on roots and leaves for the 4 nutrient treatments (Full, LowN, LowP and lowNP) and two replicates, for a total of 2 tissues $\times$ 4 treatments $\times 2$ replicates $=16$ samples. Libraries were prepared by the Laboratorio de Servicios Genomicos, LANGEBIO, Mexico (www.langebio.cinvestav.mx/ labsergen/). Libraries were prepared using the TruSeq RNA Sample Prep Kit v2 (https://support.illumina.com/ sequencing/sequencing_kits/truseq_rna_sample_prep_ kit_v2.html) and sequenced using the Illumina HiSeq4000 platform at the Vincent J. Coates Genomics Sequencing Laboratory at UC Berkeley, supported by NIH S10 OD018174 Instrumentation Grant, and at Labsergen on the Illumina NextSeq 550 equipment. Transcriptome data are available in the NCBI Sequence Read Archive under study SRP287300 at https://trace.ncbi. nlm.nih.gov/Traces/sra/?study=SRP287300

RNA sequencing reads were aligned against the AGPV3.30 maize gene model set available at Ensembl Plants [106] using kallisto version 0.43.1 [107]). Transcript-level abundance data was pre-processed using R/tximport [108] and summarized at the genelevel before further analysis. Count data were analyzed using a linear model approach in edgeR $[109,110]$. We fitted the complete model counts $\sim$ intercept + tissue * $N$ level * P-level + error across the 16 samples. We selected genes-of-interest based on evidence of a non-zero coefficient for at least one model term containing $N$-level or P-level (the coef argument to R/edgeR::glmQLFTest included all model coefficients except for the intercept and tissue main effect; adjusted FDR $<0.01$; absolute log fold change $(\mathrm{LFC})>1$; $\log$ counts per million $(\mathrm{CPM})>1$ ). An additional subset of $81 \mathrm{NxP}$ interaction genes was selected based on the coefficients $N$-level $\times$ P-level and tissue $\mathrm{x} N$-level $\times$ P-level (adjusted FDR $<0.05 ;|\mathrm{LFC}|>1$; $\log \mathrm{CPM}>1$ ). Genes-of-interest were further categorized based on pairwise LFC for each stress treatment with respect to the full nutrient control for either root or leaves. LFC for each tissue was extracted from the model counts $\sim$ treatment + error, a threshold of +1 and -1 being used for up- and down- regulation, respectively. Gene functional annotations were assigned as the functional annotation of the blastp reciprocal best hits versus Araport11 [https://doi.org/10.1111/tpj.13415] and uniprot proteins, and the description from the PANNZER2 [https://doi.org/ 10.1093/nar/gky350] functional annotation webserve. Upset diagrams were generated using R/UpSetR and R/ ComplexHeatmap [111, 112]. GO analysis was performed with BiNGO 3.0.3 [113] in the Cytoscape 3.7.2 environment [114] using a hypergeometric test, Benjamini \& Hochberg FDR correction and a significance level of 0.05 . The Gene ontology file (go.obo) was retrieved from the gene ontology web page (http://geneontology.org/docs/ download-ontology/). For each GO category, the mean LFC of the associated genes-of-interest was calculated with respect to each tissue/treatment combination using the pairwise values described above.

\section{Real-time PCR}

For real-time PCR transcript quantification, leaves and roots of five biological replicates per treatment were analyzed. Total RNA was extracted using Trizol and cDNAs were synthesized using SuperScript ${ }^{\circ}$ II Reverse Transcriptase from Invitrogen (Cat No. 18064071). RTPCR was performed using 96 well plates in a LightCycler 480 Instrument by Roche. PCR reactions were performed using KAPA SYBR FAST qPCR Master Mix kit by Kapa Biosystems, with the following cycling conditions: $95^{\circ} \mathrm{C}$ for $7 \mathrm{~min}$, followed by 40 cycles of $95^{\circ} \mathrm{C}$ for 15 seg; $60^{\circ} \mathrm{C}$ for $20 \mathrm{seg} ; 72^{\circ} \mathrm{C}$ for $20 \mathrm{seg}$. The final reaction volume was $10 \mu \mathrm{l}$ including $1 \mu \mathrm{l}$ of each $5 \mu \mathrm{M}$ primer, $1 \mu \mathrm{l}$ of $(40 \mathrm{ng} / \mu \mathrm{l})$ template cDNA, $5 \mu \mathrm{l}$ of SYBR Master Mix and $2 \mu \mathrm{l}$ of distilled water. The relative quantification of the gene expression was determined as $2^{\Delta \mathrm{Ct}}$, where $\Delta \mathrm{Ct}=2^{\wedge}$ (Average Ct of reference genes - Ct of gene of interest) [115]. Values reported are the mean of five biological replicas \pm SE of one representative experiment. Previously described reference genes [116] were used as controls: Cyclin-Dependent Kinase $(C d k$; GRMZM2G149286) and a gene encoding an uncharacterized protein (Unknown; GRMZM2G047204). PCR primers were designed using Primer3Plus software [117] and are listed in MZ95_RT_Primers in Supplemental File 3.

\section{Phylogenetic analysis of the SPX-domain protein family}

Maize putative SPX-domain protein encoding genes were identified using a methodology previously described for the maize Pap gene family [58]. Briefly, Arabidopsis and rice proteins [64] were retrieved and aligned using MUSCLE v3.8 [118]. The alignment was then converted to Stockholm format. B73 maize primary transcript predicted protein sequences v3.31 [119] obtained from Ensembl Plants [106] were searched using HMMER suite version 3.1b2 [120]. After manually checking and filtering for proteins lacking the canonical SPX domain [121], 15 putative SPX-protein sequences were identified. Where noted, gene models annotated in the v4 genome assembly were preferred. For phylogenetic analysis, Arabidopsis, rice and maize SPX proteins were aligned using MUSCLE [118] and passed to MEGA version X [122, 123]. We manually selected SPX subdomains defined by [87] and corrected mismatches in the alignment (Fig. S3). A 1000 bootstrap phylogenetic tree was constructed with Maximum Likelihood method and Le_Gascuel_2008 model [124]. 


\section{Abbreviations}

DAE: Days After Emergence; FDR: False Discovery Rate; GO: Gene Ontology; ICP-MS: Inductively Coupled Plasma Mass Spectrometry; LFC: Log 2 Fold Change; NSR: Nitrogen Starvation Response; PCR: Polymerase Chain Reaction; PSR: Phosphate Starvation Response

\section{Supplementary Information}

The online version contains supplementary material available at https://doi. org/10.1186/s12870-021-02997-5.

Additional file 1: Figure S1. Growth traits for plants grown under Full, LowN, LowP and LowNP. Plots show estimated coefficient and associated standard error. The significance of the treatment effect is shown as *** $p<0.001,{ }^{* *} p<0.01,{ }^{*} p<0.05, p<0.1$ (Kruskal-Wallis test; $\mathrm{p}$-value adjusted for multiple tests). Lowercase letters indicate significant $(p<0.05)$ pairwise differences (Dunn test). Figure accompanies MZ66_Growth_Analysis in Supplemental File 1.

Additional file 2: Figure S2. Endpoint traits for plants grown under Full, LowN, LowP and LowNP. Plots show estimated coefficient and associated standard error. The significance of the treatment effect is shown as ${ }^{* *} p<0.001,{ }^{* *} p<0.01,{ }^{*} p<0.05, p<0.1$ (Kruskal-Wallis test; $\mathrm{p}$-value adjusted for multiple tests). Lowercase letters indicate significant $(p<0.05)$ pairwise differences (Dunn test). Figure accompanies MZ66_Endpoint_Analysis in Supplemental File 1.

Additional file 3: Figure S3. GiaRoot root features for plants grown under Full, LowN, LowP and LowNP. Plots show estimated coefficient and associated standard error. The significance of the treatment effect is shown as ${ }^{* * *} p<0.001,{ }^{* *} p<0.01,{ }^{*} p<0.05, p<0.1$ (Kruskal-Wallis test; $p$-value adjusted for multiple tests). Lowercase letters indicate significant $(p<0.05)$ pairwise differences (Dunn test). Figure accompanies MZ66_Giaroots_Analysis in Supplemental File 1.

Additional file 4: Figure S4. lons concentrations for plants grown under Full, LowN, LowP and LowNP. Plots show estimated coefficient and associated standard error. The significance of the treatment effect is shown as ${ }^{* * *} p<0.001,{ }^{* *} p<0.01,{ }^{*} p<0.05, p<0.1$ (ANOVA; $\mathrm{p}$-value adjusted for multiple tests). Lowercase letters indicate significant $(p<0.05)$ pairwise differences (Tukey). Figure accompanies MZ66_lonomics_Analysis in Supplemental File 1.

Additional file 5: Figure S5. Transcription of PSR is reduced under LowN availability. Scatter plot showing the distribution of transcript accumulation ( $\log _{2}$ fold change, LFC) of 1, 555 genes in A) leaves and B) roots in LowP and lowN. Dotted lines represent LFC of -1 and 1. Dots filled using heat-colors showing LowNP transcript accumulation. C) Differential transcript accumulation ( $\mathrm{z}$, row standardized LFC) with respect to Full of the top 30 (ranked by FDR) classic genes. Figure accompanies MZ67_Selected_Classics in Supplemental File 2.

Additional file 6: Figure S6. SPX-domain family members respond to reduced $\mathrm{N}$ and $\mathrm{P}$ availability. A) Phylogenetic tree of SPX-domain family proteins in maize. Likelihood tree built with Arabidopsis, rice and maize SPX-domain proteins. Numbers at the nodes indicate bootstrap (1000) support as percentage. B) Heat map of maize SPX-domain gene family expression under LowN, LowP and combined LowNP with respect to Full ( $z$, row standardized $\log _{2}$ fold change). Asterisks indicate genes identified as regulated in the transcriptome analysis.

Additional file 7: Supplemental file 1. Plant growth to 40 days after emergence (experiment MZ66). Workbook contains raw and processed phenotypic data from maize plants under lowN, lowP and lowNP until 40 days after emergence.

Additional file 8: Supplemental file 2. Transcriptome analysis of from maize plants under lowN, lowP and lowNP until 25 days after emergence (experiment MZ67). Workbook contains count data, analysis, candidate gene lists and annotation, and enriched GO terms.

Additional file 9: Supplemental file 3. MZ95 experiment. File contains phenotypic and gene expression data from qRT-PCR of maize leaves and roots under LowN, LowP and lowNP at 25 days after emergence. Workbook contains expression data and analysis.

\section{Acknowledgements}

We thank Benjamin Barrales-Gamez, Ana Laura Alonso-Nieves and Jessica Carcaño-Macias for assistance in plant growth and harvest. We thank Ivan Baxter (Danforth Center, MO, USA) for supporting ICP-MS analysis.

\section{Authors' contributions}

JVT-R and MNS-V conceived and designed the experiments, performed the experiments, analyzed the data, prepared figures and tables and authored drafts of the paper. RACM analyzed RNA-seq data and authored drafts of the paper. JAM-S performed experiments, analyzed the data, and authored drafts of the paper. CSG conceived and designed the experiments, contributed reagents/materials/analysis tools and authored or reviewed drafts of the paper. RJHS conceived and designed the experiments, analyzed the data, contributed reagents/materials/analysis tools, prepared figures and/or tables, authored or reviewed drafts of the paper. All authors approved the final draft.

\section{Funding}

The funders had no role in study design, data collection and analysis, decision to publish, or preparation of the manuscript.

This work was supported by the Mexican Consejo Nacional de Ciencia y Tecnología (CB-2015-01 254012).

RJHS is supported by the USDA National Institute of Food and Agriculture and Hatch Appropriations under Project \#PEN04734 and Accession $\# 1021929$.

\section{Availability of data and materials}

Transcriptome data are available in the NCBI Sequence Read Archive under study SRP287300 at https://trace.ncbi.nlm.nih.gov/Traces/sra/?study=SRP2873 00

\section{Declarations}

Ethics approval and consent to participate

Not applicable.

\section{Consent for publication}

Not applicable.

\section{Competing interests}

The authors declare that they have no competing interests.

\section{Author details}

'Laboratorio Nacional de Genómica para la Biodiversidad (Langebio), Unidad de Genómica Avanzada, Centro de Investigación y de Estudios Avanzados del Instituto Politécnico Nacional (CINVESTAV-IPN), Irapuato, C.P, 36824 Guanajuato, Mexico. ${ }^{2}$ Department of Evolution and Ecology, University of California-Davis, One Shields Avenue, Davis, CA 95616, USA. ${ }^{3}$ Division of Plant Sciences, Univ. of Missouri, Columbia, MO 65211, USA. ${ }^{4}$ Institute of Genomics for Crop Abiotic Stress Tolerance, Texas Tech University, Lubbock, TX 79409, USA. ${ }^{5}$ Unidad de Biotecnología Vegetal, Centro de Investigación y Asistencia en Tecnología y Diseño del Estado de Jalisco A.C. (CIATEJ) Subsede Zapopan, Guadalajara, Mexico. ${ }^{6}$ Department of Plant Science, The Pennsylvania State University, State College, PA, USA.

Received: 30 October 2020 Accepted: 30 April 2021

Published online: 05 June 2021

References

1. Ho C-H, Lin S-H, Hu H-C, Tsay Y-F. CHL1 functions as a nitrate sensor in plants. Cell. 2009;138(6):1184-94. https://doi.org/10.1016/j.cell.2009.07.004.

2. Plaxton WC, Tran HT. Metabolic adaptations of phosphate-starved plants. Plant Physiol. 2011;156(3):1006-15. https://doi.org/10.1104/pp.111.175281.

3. Péret B, Clément M, Nussaume L, Desnos T. Root developmental adaptation to phosphate starvation: better safe than sorry. Trends Plant Sci. 2011;16(8): 442-50. https://doi.org/10.1016/j.tplants.2011.05.006.

4. Veneklaas EJ, Lambers H, Bragg J, Finnegan PM, Lovelock CE, Plaxton WC et al. Opportunities for improving phosphorus-use efficiency in crop plants. New Phytol. 2012;195(2):306-20. https://doi.org/10.1111/j.1469-8137.2012. 04190.x. 
5. Yang W, Yoon J, Choi H, Fan Y, Chen R, An G. Transcriptome analysis of nitrogen-starvation-responsive genes in rice. BMC Plant Biol. 2015;15(1):31. https://doi.org/10.1186/s12870-015-0425-5.

6. Raghothama KG. PHOSPHATE ACQUISITION. Annu Rev Plant Physiol Plant Mol Biol. 1999;50(1):665-93. https://doi.org/10.1146/annurev.arplant.50.1.665.

7. Good AG, Shrawat AK, Muench DG. Can less yield more? Is reducing nutrient input into the environment compatible with maintaining crop production? Trends Plant Sci. 2004;9(12):597-605. https://doi.org/10.1016/j. tplants.2004.10.008.

8. Hinsinger $P$. Bioavailability of soil inorganic $P$ in the rhizosphere as affected by root-induced chemical changes: a review. Plant Soil. 2001;237(2):173-95. https://doi.org/10.1023/A:1013351617532.

9. López-Arredondo DL, Leyva-González MA, González-Morales SI, López-Bucio J, Herrera-Estrella L. Phosphate nutrition: improving low-phosphate tolerance in crops. Annu Rev Plant Biol. 2014;65(1):95-123. https://doi.org/1 0.1146/annurev-arplant-050213-035949.

10. Saengwilai $P$, Tian $X$, Lynch JP. Low crown root number enhances nitrogen acquisition from low-nitrogen soils in maize. Plant Physiol. 2014;166(2):5819. https://doi.org/10.1104/pp.113.232603.

11. Lynch JP. Root phenotypes for improved nutrient capture: an underexploited opportunity for global agriculture. New Phytol. 2019;223(2): 548-64. https://doi.org/10.1111/nph.15738.

12. Lv C, Yan C, Chen G, Ding Y, Sun J, Zhou Y, et al. An amorphous Noblemetal-free Electrocatalyst that enables nitrogen fixation under ambient conditions. Angew Chem. 2018;130(21):6181-4. https://doi.org/10.1002/a nge.201801538.

13. Vance $C P$, Uhde-Stone C, Allan DL. Phosphorus acquisition and use: critical adaptations by plants for securing a nonrenewable resource. New Phytol. 2003;157(3):423-47. https://doi.org/10.1046/j.1469-8137.2003.00695.x.

14. Herrera-Estrella L, López-Arredondo D. Phosphorus: the underrated element for feeding the world. Trends Plant Sci. 2016;21(6):461-3. https://doi.org/10.1 016/j.tplants.2016.04.010.

15. Schlüter U, Colmsee C, Scholz U, Bräutigam A, Weber APM, Zellerhoff N, et al. Adaptation of maize source leaf metabolism to stress related disturbances in carbon, nitrogen and phosphorus balance. BMC Genomics. 2013;14(1):442. https://doi.org/10.1186/1471-2164-14-442.

16. Varala K, Marshall-Colón A, Cirrone J, Brooks MD, Pasquino AV, Léran S, et al. Temporal transcriptional logic of dynamic regulatory networks underlying nitrogen signaling and use in plants. Proc Natl Acad Sci U S A. 2018;115(25): 6494-9. https://doi.org/10.1073/pnas.1721487115.

17. Xin W, Zhang L, Zhang W, Gao J, Yi J, Zhen X, et al. An integrated analysis of the Rice Transcriptome and Metabolome reveals root growth regulation mechanisms in response to nitrogen availability. Int J Mol Sci. 2019;20(23). https://doi.org/10.3390/ijms20235893.

18. Tyagi W, Rai M. Root transcriptomes of two acidic soil adapted Indica rice genotypes suggest diverse and complex mechanism of low phosphorus tolerance. Protoplasma. 2017;254(2):725-36. https://doi.org/10.1007/s00709016-0986-7.

19. Subudhi PK, Garcia RS, Coronejo S, Tapia R. Comparative Transcriptomics of Rice genotypes with contrasting responses to nitrogen stress reveals genes influencing nitrogen uptake through the regulation of root architecture. Int J Mol Sci. 2020;21(16). https://doi.org/10.3390/ijms21165759.

20. Shin S-Y, Jeong JS, Lim JY, Kim T, Park JH, Kim J-K, et al. Transcriptomic analyses of rice (Oryza sativa) genes and non-coding RNAs under nitrogen starvation using multiple omics technologies. BMC Genomics. 2018;19(1): 532. https://doi.org/10.1186/s12864-018-4897-1.

21. Feng $H$, Yan M, Fan X, Li B, Shen Q, Miller AJ, et al. Spatial expression and regulation of rice high-affinity nitrate transporters by nitrogen and carbon status. J Exp Bot. 2011;62(7):2319-32. https://doi.org/10.1093/jxb/erq403.

22. Lezhneva L, Kiba T, Feria-Bourrellier A-B, Lafouge F, Boutet-Mercey S, Zoufan $P$, et al. The Arabidopsis nitrate transporter NRT2.5 plays a role in nitrate acquisition and remobilization in nitrogen-starved plants. Plant J. 2014;80: 230-41. https://doi.org/10.1111/tpj.12626.

23. Dechorgnat J, Francis KL, Dhugga KS, Rafalski JA, Tyerman SD, Kaiser BN. Tissue and nitrogen-linked expression profiles of ammonium and nitrate transporters in maize. BMC Plant Biol. 2019;19:206. https://doi.org/10.1186/ s12870-019-1768-0.

24. Mudge SR, Rae AL, Diatloff E, Smith FW. Expression analysis suggests novel roles for members of the Pht1 family of phosphate transporters in Arabidopsis. Plant J. 2002;31(3):341-53. https://doi.org/10.1046/j.1365-313X.2 002.01356.x.
25. Paszkowski U, Kroken S, Roux C, Briggs SP. Rice phosphate transporters include an evolutionarily divergent gene specifically activated in arbuscular mycorrhizal symbiosis. Proc Natl Acad Sci U S A. 2002;99(20):13324-9. https://doi.org/10.1073/pnas.202474599.

26. Wang $X$, Wang Y, Piñeros MA, Wang Z, Wang W, Li C, et al. Phosphate transporters OsPHT1;9 and OsPHT1;10 are involved in phosphate uptake in rice. Plant Cell Environ. 2014;37(5):1159-70. https://doi.org/10.1111/pce.12224.

27. Liu F, Xu Y, Jiang H, Jiang C, Du Y, Gong C, et al. Systematic identification, evolution and expression analysis of the Zea mays PHT1 gene family reveals several new members involved in root colonization by arbuscular mycorrhizal fungi. Int J Mol Sci. 2016;17(6):930. https://doi.org/10.3390/ijms17060930.

28. Schluter U, Mascher M, Colmsee C, Scholz U, Brautigam A, Fahnenstich H, et al. Maize source leaf adaptation to nitrogen deficiency affects not only nitrogen and carbon metabolism but also control of phosphate homeostasis. Plant Physiol. 2012;160(3):1384-406. https://doi.org/10.1104/pp.112.204420.

29. Wasaki J, Yonetani R, Kuroda S, Shinano T, Yazaki J, Fujii F, et al. Transcriptomic analysis of metabolic changes by phosphorus stress in rice plant roots. Plant Cell Environ. 2003;26(9):1515-23. https://doi.org/10.1046/ j.1365-3040.2003.01074.x.

30. Secco D, Jabnoune M, Walker H, Shou H, Wu P, Poirier Y, et al. Spatiotemporal transcript profiling of rice roots and shoots in response to phosphate starvation and recovery. Plant Cell. 2013;25(11):4285-304. https:// doi.org/10.1105/tpc.113.117325.

31. Lin H-J, Gao J, Zhang Z-M, Shen Y-O, Lan H, Liu L, et al. Transcriptional responses of maize seedling root to phosphorus starvation. Mol Biol Rep. 2013;40(9):5359-79. https://doi.org/10.1007/s11033-013-2636-x.

32. Jiang L, Ball G, Hodgman C, Coules A, Zhao H, Lu C. Analysis of gene regulatory networks of maize in response to nitrogen. Genes. 2018;9. doi: https://doi.org/10.3390/genes9030151.

33. Wang X, Wang H-F, Chen Y, Sun M-M, Wang Y, Chen Y-F. The Transcription Factor NIGT1.2 Modulates Both Phosphate Uptake and Nitrate Influx during Phosphate Starvation in Arabidopsis and Maize. Plant Cell. 2020. doi:https:// doi.org/10.1105/tpc.20.00361.

34. Cakmak I, Marschner H. Mechanism of phosphorus-induced zinc deficiency in cotton. I. Zinc deficiency-enhanced uptake rate of phosphorus. Physiol Plant. 1986;68(3):483-90. https://doi.org/10.1111/j.1399-3054.1986.tb03386.x.

35. Pilbeam DJ, Cakmak I, Marschner H, Kirkby EA. Effect of withdrawal of phosphorus on nitrate assimilation and PEP carboxylase activity in tomato. In: Fragoso MAC, Van Beusichem ML, Houwers A, editors. Optimization of plant nutrition: refereed papers from the eighth international colloquium for the optimization of plant nutrition, 31 august - 8 September 1992, Lisbon, Portugal. Dordrecht: Springer Netherlands; 1993. p. 555-561, DOI: https:// doi.org/10.1007/978-94-017-2496-8_86.

36. Ward JT, Lahner B, Yakubova E, Salt DE, Raghothama KG. The effect of iron on the primary root elongation of Arabidopsis during phosphate deficiency. Plant Physiol. 2008;147(3):1181-91. https://doi.org/10.1104/pp.108.118562.

37. Kellermeier F, Armengaud P, Seditas TJ, Danku J, Salt DE, Amtmann A. Analysis of the root system architecture of Arabidopsis provides a quantitative readout of crosstalk between nutritional signals. Plant Cell. 2014;26(4):1480-96. https://doi.org/10.1105/tpc.113.122101.

38. Bonneau L, Huguet S, Wipf D, Pauly N, Truong H-N. Combined phosphate and nitrogen limitation generates a nutrient stress transcriptome favorable for arbuscular mycorrhizal symbiosis in Medicago truncatula. New Phytol. 2013;199(1):188-202. https://doi.org/10.1111/nph.12234.

39. Dissanayake I, Rodriguez-Medina J, Brady SM, Tanurdžić M. Transcriptional dynamics of bread wheat in response to nitrate and phosphate supply reveal functional divergence of genetic factors involved in nitrate and phosphate signaling. Cold Spring Harbor Laboratory. 2019. doi:https://doi. org/10.1101/551069.

40. Medici A, Szponarski W, Dangeville P, Safi A, Dissanayake IM, Saenchai C, et al. Identification of molecular integrators shows that nitrogen actively controls the phosphate starvation response in plants. Plant Cell. 2019;31(5): 1171-84. https://doi.org/10.1105/tpc.18.00656.

41. Peng M, Hannam C, Gu H, Bi Y-M, Rothstein SJ. A mutation in NLA, which encodes a RING-type ubiquitin ligase, disrupts the adaptability of Arabidopsis to nitrogen limitation. Plant J. 2007:50(2):320-37. https://doi. org/10.1111/j.1365-313X.2007.03050.X.

42. Kant S, Peng M, Rothstein SJ. Genetic regulation by NLA and MicroRNA827 for maintaining nitrate-dependent phosphate homeostasis in Arabidopsis. PLoS Genet. 2011;7(3):e1002021. https://doi.org/10.1371/ journal.pgen.1002021. 
43. Lin W-Y, Huang T-K, Chiou T-J. NITROGEN LIMITATION ADAPTATION, a target of MicroRNA827, mediates degradation of plasma membranelocalized phosphate transporters to maintain phosphate homeostasis in Arabidopsis. Plant Cell. 2013;25(10):4061-74. https://doi.org/10.1105/ tpc.113.116012.

44. Liu W, Sun Q, Wang K, Du Q, Li W-X. Nitrogen Limitation Adaptation (NLA) is involved in source-to-sink remobilization of nitrate by mediating the degradation of NRT1.7 in Arabidopsis. New Phytol. 2017;214:734-44. https:// doi.org/10.1111/nph.14396.

45. Yue W, Ying Y, Wang C, Zhao Y, Dong C, Whelan J, et al. OsNLA1, a RINGtype ubiquitin ligase, maintains phosphate homeostasis in Oryza sativa via degradation of phosphate transporters. Plant J. 2017;90(6):1040-51. https:// doi.org/10.1111/tpj.13516.

46. Zhong S, Mahmood K, Bi Y-M, Rothstein SJ, Ranathunge K. Altered Expression of OsNLA1 Modulates Pi Accumulation in Rice ( L.) Plants. Front Plant Sci. 2017;8:928. https://doi.org/10.3389/fpls.2017.00928.

47. Lin W-Y, Lin Y-Y, Chiang S-F, Syu C, Hsieh L-C, Chiou T-J. Evolution of microRNA827 targeting in the plant kingdom. New Phytol. 2018;217(4): 1712-25. https://doi.org/10.1111/nph.14938.

48. Rubio V, Linhares F, Solano R, Martín AC, Iglesias J, Leyva A, et al. A conserved MYB transcription factor involved in phosphate starvation signaling both in vascular plants and in unicellular algae. Genes Dev. 2001; 15(16):2122-33. https://doi.org/10.1101/gad.204401.

49. LV Q, Zhong Y, Wang $Y$, Wang Z, Zhang L, Shi J, et al. SPX4 negatively regulates phosphate signaling and homeostasis through its interaction with PHR2 in Rice. Plant Cell. 2014;26(4):1586-97. https:/doi.org/10.1105/tpc.114.123208.

50. Hu B, Jiang Z, Wang W, Qiu Y, Zhang Z, Liu Y, et al. Nitrate-NRT1.1B-SPX4 cascade integrates nitrogen and phosphorus signalling networks in plants. Nature Plants. 2019;5(4):401-13. https://doi.org/10.1038/s41477-019-0384-1.

51. Mollier A, Pellerin S. Maize root system growth and development as influenced by phosphorus deficiency. J Exp Bot. 1999;50(333):487-97. https://doi.org/10.1093/jxb/50.333.487.

52. Toledo Machado A, Fernandes MS. Participatory maize breeding for low nitrogen tolerance. Euphytica. 2001;122(3):567-73. https://doi.org/10.1 023/A:1017543426136.

53. Lynch JP, Brown KM. Root strategies for phosphorus acquisition. In: White PJ, Hammond JP, editors. The Ecophysiology of plant-phosphorus interactions. Dordrecht: Springer Netherlands; 2008. p. 83-116. https://doi. org/10.1007/978-1-4020-8435-5_5.

54. Ajala SO, Olaniyan AB, Olayiwola MO, Job AO. Yield improvement in maize for tolerance to low soil nitrogen. Plant Breed. 2018;137(2):118-26. https:// doi.org/10.1111/pbr.12568

55. Galkovskyi T, Mileyko Y, Bucksch A, Moore B, Symonova O, Price CA, et al. GiA roots: software for the high throughput analysis of plant root system architecture. BMC Plant Biol. 2012;12(1):116. https://doi.org/10.1186/14 71-2229-12-116.

56. Guo A-Y, Chen X, Gao G, Zhang H, Zhu Q-H, Liu X-C, et al. PlantTFDB: a comprehensive plant transcription factor database. Nucleic Acids Res. 2008; 36(Database issue):D966-9. https://doi.org/10.1093/nar/gkm841.

57. Törönen P, Medlar A, Holm L. PANNZER2: a rapid functional annotation web server. Nucleic Acids Res. 2018;46(W1):W84-8. https:/doi.org/10.1093/nar/ gky350

58. González-Muñoz E, Avendaño-Vázquez A-O, Montes RAC, de Folter S, Andrés-Hernández L, Abreu-Goodger C, et al. The maize (Zea mays ssp. mays var. B73) genome encodes 33 members of the purple acid phosphatase family. Front. Plant Sci. 2015;6:341. https://doi.org/10.3389/ fpls.2015.00341

59. Calderón-Vázquez C, Sawers RJH, Herrera-Estrella L. Phosphate deprivation in maize: genetics and genomics. Plant Physiol. 2011;156(3):1067-77. https:// doi.org/10.1104/pp.111.174987.

60. Młodzińska E, Zboińska M. Phosphate Uptake and Allocation - A Closer Look at Arabidopsis thaliana L and Oryza sativa L. Front Plant Sci. 2016;7:1198. https://doi.org/10.3389/fpls.2016.01198.

61. Jung J-Y, Ried MK, Hothorn M, Poirier Y. Control of plant phosphate homeostasis by inositol pyrophosphates and the SPX domain. Curr Opin Biotechnol. 2018:49:156-62. https://doi.org/10.1016/j.copbio.2017.08.012.

62. Ham B-K, Chen J, Yan Y, Lucas WJ. Insights into plant phosphate sensing and signaling. Curr Opin Biotechnol. 2018;49:1-9. https://doi.org/10.1016/j. copbio.2017.07.005.

63. Trevisan S, Manoli A, Begheldo M, Nonis A, Enna M, Vaccaro S, et al. Transcriptome analysis reveals coordinated spatiotemporal regulation of hemoglobin and nitrate reductase in response to nitrate in maize roots. New Phytol. 2011;192(2):338-52. https://doi.org/10.1111/j.1469-8137.2011.03822.x.

64. Ho MD, McCannon BC, Lynch JP. Optimization modeling of plant root architecture for water and phosphorus acquisition. J Theor Biol. 2004;226(3): 331-40. https://doi.org/10.1016/j.jtbi.2003.09.011.

65. Postma JA, Dathe A, Lynch JP. The optimal lateral root branching density for maize depends on nitrogen and phosphorus availability. Plant Physiol. 2014;166(2):590-602. https://doi.org/10.1104/pp.113.233916.

66. Rangarajan H, Postma JA, Lynch JP. Co-optimization of axial root phenotypes for nitrogen and phosphorus acquisition in common bean. Ann Bot. 2018;122(3):485-99. https://doi.org/10.1093/aob/mcy092.

67. Li D, Zhu H, Liu K, Liu X, Leggewie G, Udvardi M, et al. Purple acid phosphatases of Arabidopsis thaliana. Comparative analysis and differential regulation by phosphate deprivation. J Biol Chem. 2002;277(31):27772-81. https://doi.org/10.1074/jbc.M204183200.

68. Hurley BA, Tran HT, Marty NJ, Park J, Snedden WA, Mullen RT, et al. The dual-targeted purple acid phosphatase isozyme AtPAP26 is essential for efficient acclimation of Arabidopsis to nutritional phosphate deprivation. Plant Physiol. 2010;153(3):1112-22. https://doi.org/10.1104/pp.110.153270.

69. Zhang Q, Wang C, Tian J, Li K, Shou H. Identification of rice purple acid phosphatases related to posphate starvation signalling. Plant Biol. 2011; 13(1):7-15. https://doi.org/10.1111/j.1438-8677.2010.00346.x.

70. Nakamura Y. Phosphate starvation and membrane lipid remodeling in seed plants. Prog Lipid Res. 2013;52(1):43-50. https://doi.org/10.1016/j.plipres.2 012.07.002.

71. Pant BD, Burgos A, Pant P, Cuadros-Inostroza A, Willmitzer L, Scheible W-R. The transcription factor PHR1 regulates lipid remodeling and triacylglycerol accumulation in Arabidopsis thaliana during phosphorus starvation. J Exp Bot. 2015;66(7):1907-18. https://doi.org/10.1093/jxb/eru535.

72. Yang XS, Wu J, Ziegler TE, Yang X, Zayed A, Rajani MS, et al. Gene expression biomarkers provide sensitive indicators of in planta nitrogen status in maize. Plant Physiol. 2011;157(4):1841-52. https://doi.org/10.1104/ pp.111.187898.

73. Ma N, Dong L, Lü W, Lü J, Meng Q, Liu P. Transcriptome analysis of maize seedling roots in response to nitrogen-, phosphorus-, and potassium deficiency. Plant Soil. 2020;447(1-2):637-58. https://doi.org/10.1007/s11104019-04385-3.

74. Hsieh P-H, Kan C-C, Wu H-Y, Yang H-C, Hsieh M-H. Early molecular events associated with nitrogen deficiency in rice seedling roots. Sci Rep. 2018;8(1): 12207. https://doi.org/10.1038/s41598-018-30632-1.

75. Krapp A, Berthomé R, Orsel M, Mercey-Boutet S, Yu A, Castaings L, Elftieh S, Major H, Renou J-P, Daniel-Vedele F. Arabidopsis Roots and Shoots Show Distinct Temporal Adaptation Patterns toward Nitrogen Starvation, Plant Physiology. 2011;157(3):1255-82. https://doi.org/10.11 04/pp.111.179838.

76. Swift J, Alvarez JM, Araus V, Gutiérrez RA, Coruzzi GM. Nutrient doseresponsive transcriptome changes driven by Michaelis-Menten kinetics underlie plant growth rates. Proc Natl Acad Sci U S A. 2020;117(23):1253140. https://doi.org/10.1073/pnas.1918619117.

77. González E, Solano R, Rubio V, Leyva A, Paz-Ares J. PHOSPHATE TRAN SPORTER TRAFFIC FACILITATOR1 is a plant-specific SEC12-related protein that enables the endoplasmic reticulum exit of a high-affinity phosphate transporter in Arabidopsis. Plant Cell. 2005;17(12):3500-12. https://doi.org/1 0.1105/tpc.105.036640

78. Park BS, Seo JS, Chua N-H. NITROGEN LIMITATION ADAPTATION recruits PHOSPHATE2 to target the PHOSPHATE transporter PT2 for degradation during the regulation of Arabidopsis phosphate homeostasis. Plant Cell. 2014;26(1):454-64. https://doi.org/10.1105/tpc.113.120311.

79. Chiou T-J, Aung K, Lin S-I, Wu C-C, Chiang S-F, Su C-L. Regulation of phosphate homeostasis by MicroRNA in Arabidopsis. Plant Cell. 2006;18(2): 412-21. https://doi.org/10.1105/tpc.105.038943.

80. Pant BD, Buhtz A, Kehr J, Scheible W-R. MicroRNA399 is a long-distance signal for the regulation of plant phosphate homeostasis. Plant J. 2008;53(5): 731-8. https://doi.org/10.1111/j.1365-313X.2007.03363.x.

81. Bari R, Datt Pant B, Stitt M, Scheible W-R. PHO2, microRNA399, and PHR1 define a phosphate-signaling pathway in plants. Plant Physiol. 2006;141(3): 988-99. https://doi.org/10.1104/pp.106.079707.

82. Hu B, Zhu C, Li F, Tang J, Wang $Y$, Lin A, et al. LEAF TIP NECROSIS1 plays a pivotal role in the regulation of multiple phosphate starvation responses in rice. Plant Physiol. 2011;156(3):1101-15. https://doi.org/1 $0.1104 /$ pp. 110.170209 
83. Du Q, Wang K, Zou C, Xu C, Li W-X. The PILNCR1-miR399 regulatory module is important for low phosphate tolerance in maize. Plant Physiol. 2018; 177(4):1743-53. https://doi.org/10.1104/pp.18.00034.

84. Xu Z, Zhong S, Li X, Li W, Rothstein SJ, Zhang S, et al. Genome-wide identification of microRNAs in response to low nitrate availability in maize leaves and roots. PLoS One. 2011;6(11):e28009. https://doi.org/10.1371/ journal.pone.0028009.

85. Zhao M, Tai H, Sun S, Zhang F, Xu Y, Li W-X. Cloning and characterization of maize miRNAs involved in responses to nitrogen deficiency. PLoS One. 2012;7:e29669. https://doi.org/10.1371/journal.pone.0029669.

86. Rouached H, Bulak Arpat A, Poirier Y. Regulation of phosphate starvation responses in plants: signaling players and cross-talks. Mol Plant. 2010;3(2): 288-99. https://doi.org/10.1093/mp/ssp120.

87. Secco D, Wang C, Arpat BA, Wang Z, Poirier Y, Tyerman SD, et al. The emerging importance of the SPX domain-containing proteins in phosphate homeostasis. New Phytol. 2012;193(4):842-51. https://doi.org/10.1111/j.14698137.2011.04002.x

88. Wang Z, Hu H, Huang H, Duan K, Wu Z, Wu P. Regulation of OsSPX1 and OsSPX3 on expression ofOsSPXdomain genes and pi-starvation signaling in Rice. J Integr Plant Biol. 2009;51(7):663-74. https://doi.org/10.1111/j.17447909.2009.00834.x

89. Zhong Y, Wang Y, Guo J, Zhu X, Shi J, He Q, et al. Rice SPX6 negatively regulates the phosphate starvation response through suppression of the transcription factor PHR2. New Phytol. 2018;219(1):135-48. https://doi.org/1 $0.1111 /$ nph.15155.

90. Wang C, Ying S, Huang H, Li K, Wu P, Shou H. Involvement of OsSPX1 in phosphate homeostasis in rice. Plant J. 2009;57(5):895-904. https://doi.org/1 0.1111/j.1365-313X.2008.03734.x.

91. Rouached H, Stefanovic A, Secco D, Bulak Arpat A, Gout E, Bligny R, et al. Uncoupling phosphate deficiency from its major effects on growth and transcriptome via PHO1 expression in Arabidopsis. Plant J. 2011;65(4):55770. https://doi.org/10.1111/j.1365-313X.2010.04442.x.

92. Salazar-Vidal MN, Acosta-Segovia E, Sánchez-León N, Ahern KR, Brutnell TP, Sawers RJH. Characterization and transposon mutagenesis of the maize (Zea mays) Pho1 gene family. PLoS One. 2016;11(9):e0161882. https://doi.org/1 0.1371/journal.pone.0161882.

93. Liu T-Y, Huang T-K, Yang S-Y, Hong Y-T, Huang S-M, Wang F-N, et al. Identification of plant vacuolar transporters mediating phosphate storage. Nat Commun. 2016;7(1):11095. https://doi.org/10.1038/ ncomms 11095 .

94. Xu L, Zhao H, Wan R, Liu Y, Xu Z, Tian W, et al. Identification of vacuolar phosphate efflux transporters in land plants. Nat Plants. 2019;5(1):84-94 https://doi.org/10.1038/s41477-018-0334-3.

95. Lin S-I, Santi C, Jobet E, Lacut E, El Kholti N, Karlowski WM, et al. Complex regulation of two target genes encoding SPX-MFS proteins by Rice miR827 in response to phosphate starvation. Plant Cell Physiol. 2010;51(12):2119-31. https://doi.org/10.1093/pcp/pcq170.

96. Wang C, Huang W, Ying Y, Li S, Secco D, Tyerman S, et al. Functional characterization of the rice SPX-MFS family reveals a key role of OSSPXMFS1 in controlling phosphate homeostasis in leaves. New Phytol. 2012; 196(1):139-48. https://doi.org/10.1111/j.1469-8137.2012.04227.x.

97. Hoagland DR, Broyer TC. General nature of the process of salt accumulation by roots with description of experimental methods. Plant Physiol. 1936; 11(3):471-507. https://doi.org/10.1104/pp.11.3.471.

98. Lynch J, Epstein E, Lauchli A, Weight Gl. An automated greenhouse sand culture system suitable for studies of P nutrition. Plant Cell Environ. 1990; 13(6):547-54. https://doi.org/10.1111/j.1365-3040.1990.tb01071.x.

99. Zhao D, Reddy KR, Kakani VG, Reddy VR. Nitrogen deficiency effects on plant growth, leaf photosynthesis, and hyperspectral reflectance properties of sorghum. Eur J Agron. 2005;22(4):391-403. https://doi.org/10.1016/j.eja.2 004.06.005.

100. Reddy AR, Reddy KR, Padjung R, Hodges HF. Nitrogen nutrition and photosynthesis in leaves of Pima cotton 1. J Plant Nutr. 1996;19(5):755-70. https://doi.org/10.1080/01904169609365158.

101. Ramírez-Flores MR, Rellán-Álvarez R, Wozniak B, Gebreselassie M-N, Jakobsen I, Olalde-Portugal $V$, et al. Co-ordinated changes in the accumulation of metal ions in maize (Zea mays ssp. mays L.) in response to inoculation with the Arbuscular Mycorrhizal fungus Funneliformis mosseae. Plant Cell Physiol. 2017;58(10):1689-99. https://doi.org/10.1093/pcp/pcx100.

102. R Core Team. R: A Language and Environment for Statistical Computing. 2019. https://www.R-project.org/. Accessed Jan 2020.
103. Dinno A. dunn.test: Dunn's Test of Multiple Comparisons Using Rank Sums. 2017. https://CRAN.R-project.org/package=dunn.test. Accessed Jan 2020.

104. de Mendiburu F. agricolae: Statistical Procedures for Agricultural Research. 2020. https://CRAN.R-project.org/package=agricolae. Accessed Jan 2020

105. Graves S, Piepho H-P, from Sundar Dorai-Raj LSWH. multcompView: Visualizations of Paired Comparisons. 2019. https://CRAN.R-project.org/packa ge=multcompView. Accessed Jan 2020.

106. Ensembl Plants. https://plants.ensembl.org/Zea_mays/Info/Index.

107. Bray NL, Pimentel H, Melsted P, Pachter L. Near-optimal probabilistic RNAseq quantification. Nat Biotechnol. 2016;34(5):525-7. https://doi.org/10.1038/ nbt.3519.

108. Soneson C, Love MI, Robinson MD. Differential analyses for RNA-seq: transcript-level estimates improve gene-level inferences. F1000Res. 2015; 4:1521. https://doi.org/10.12688/f1000research.7563.2.

109. Robinson MD, McCarthy DJ, Smyth GK. edgeR: a bioconductor package for differential expression analysis of digital gene expression data. Bioinformatics. 2010;26(1):139-40. https://doi.org/10.1093/bioinformatics/ btp616.

110. McCarthy DJ, Chen Y, Smyth GK. Differential expression analysis of multifactor RNA-Seq experiments with respect to biological variation. Nucleic Acids Res. 2012;40(10):4288-97. https://doi.org/10.1093/nar/gks042.

111. Conway JR, Lex A, Gehlenborg N. UpSetR: an R package for the visualization of intersecting sets and their properties. Bioinformatics. 2017;33(18):2938-40. https://doi.org/10.1093/bioinformatics/btx364.

112. Gu Z, Eils R, Schlesner M. Complex heatmaps reveal patterns and correlations in multidimensional genomic data. Bioinformatics. 2016. https:// doi.org/10.1093/bioinformatics/btw313.

113. Gu Z, Eils R, Schlesner M. Complex heatmaps reveal patterns and correlations in multidimensional genomic data. Bioinformatics. 2016;32(18): 2847-9. https://doi.org/10.1093/bioinformatics/btw313.

114. Shannon P, Markiel A, Ozier O, Baliga NS, Wang JT, Ramage D, et al. Cytoscape: a software environment for integrated models of biomolecular interaction networks. Genome Res. 2003;13(11):2498-504. https://doi.org/1 $0.1101 /$ gr.1239303.

115. Massange-Sanchez JA, Palmeros-Suarez PA, Espitia-Rangel E, RodriguezArevalo I, Sanchez-Segura L, Martinez-Gallardo NA, et al. Overexpression of grain amaranth (Amaranthus hypochondriacus) AhERF or AhDOF transcription factors in Arabidopsis thaliana increases water deficit-and saltstress tolerance, respectively, via contrasting stress-amelioration mechanisms. PLoS One. 2016;11(10):e0164280. https://doi.org/10.1371/ journal.pone.0164280.

116. Lin F, Jiang L, Liu Y, Lv Y, Dai H, Zhao H. Genome-wide identification of housekeeping genes in maize. Plant Mol Biol. 2014;86(4-5):543-54. https:// doi.org/10.1007/s11103-014-0246-1.

117. Untergasser A, Nijveen $H$, Rao X, Bisseling T, Geurts R, Leunissen JAM. Primer3Plus, an enhanced web interface to Primer3. Nucleic Acids Res. 2007; 35(Web Server issue):W71-4. https://doi.org/10.1093/nar/gkm306.

118. Edgar RC. MUSCLE: multiple sequence alignment with high accuracy and high throughput. Nucleic Acids Res. 2004;32(5):1792-7. https://doi.org/10.1 093/nar/gkh340.

119. Schnable PS, Ware D, Fulton RS, Stein JC, Wei F, Pasternak S, et al. The B73 maize genome: complexity, diversity, and dynamics. Science. 2009; 326(5956):1112-5. https://doi.org/10.1126/science.1178534.

120. Finn RD, Clements J, Eddy SR. HMMER web server: interactive sequence similarity searching. Nucleic Acids Res. 2011;39(suppl):W29-37. https://doi. org/10.1093/nar/gkr367.

121. NCBI Proteins. www.ncbi.nlm.nih.gov/protein. Accessed Jan 2020.

122. Kumar S, Stecher G, Li M, Knyaz C, Tamura K. MEGA X: Molecular evolutionary genetics analysis across computing platforms. Mol Biol Evol. 2018;35(6):1547-9. https://doi.org/10.1093/molbev/msy096.

123. Stecher G, Tamura K, Kumar S. Molecular evolutionary genetics analysis (MEGA) for macOS. Mol Biol Evol. 2020;37(4):1237-9. https://doi.org/10.1093/ $\mathrm{molbev} / \mathrm{msz} 312$.

124. Le SQ, Gascuel O. An improved general amino acid replacement matrix. Mol Biol Evol. 2008;25(7):1307-20. https://doi.org/10.1093/molbev/msn067.

\section{Publisher's Note}

Springer Nature remains neutral with regard to jurisdictional claims in published maps and institutional affiliations. 